\title{
A Strategic Plan for Strengthening America's Families: A Brief from the Coalition of Behavioral Science Organizations
}

\author{
Anthony Biglan ${ }^{1} \cdot$ Karen Elfner $^{2} \cdot$ S. Andrew Garbacz ${ }^{3} \cdot$ Kelli Komro $^{4} \cdot$ Ronald J. Prinz $^{5} \cdot$ Mark D. Weist $^{5}$. \\ Dawn K. Wilson ${ }^{5} \cdot$ Amie Zarling ${ }^{6}$
}

Published online: 28 April 2020

(c) Springer Science+Business Media, LLC, part of Springer Nature 2020

\begin{abstract}
Despite significant progress in research on the treatment and prevention of psychological, behavioral, and health problems, the translation of this knowledge into population-wide benefit remains limited. This paper reviews the state of America's children and families, highlighting the influence of stressful contextual and social conditions on child and family well-being and the concentration of disadvantage in numerous neighborhoods and communities throughout the nation. It then briefly reviews the progress that has been made in pinpointing policies that can reduce stressful contextual conditions such as poverty, discrimination, and the marketing of unhealthful foods and substances. It also describes numerous family and school interventions that have proven benefit in preventing psychological and behavioral problems as diverse as tobacco, alcohol, and other drug use; depression; antisocial behavior; academic failure; obesity prevention; and early childbearing. We argue that progress in translating existing knowledge into widespread benefit will require a nationwide effort to intervene comprehensively in neighborhoods and communities of concentrated disadvantage. We present a strategic plan for how such an effort could be organized. The first step in this organizing would be the creation of a broad and diverse coalition of organizations concerned with advancing public health and well-being. Such a coalition could increase public support both for the policies needed to focus on these disadvantaged areas and the research needed to incrementally improve our ability to help these areas.
\end{abstract}

Keywords Family wellbeing · Poverty · Concentrated disadvantage · Prevention · Child and adolescent development . Mental $\cdot$ Emotional and behavioral health

Author Notes The authors are members of the Family Nurturance Task Force convened by the Coalition of Behavioral Science Organizations (CBSO). The member organizations in the CBSO are the Association for Behavior Analysis International, the Association for Contextual Behavioral Science, the Association for Positive Behavior Support, the Evolution Institute, the National Prevention Science Coalition, and the Society for Behavioral Medicine. Order of authorship was determined alphabetically.

Anthony Biglan

tony@ori.org

Oregon Research Institute, Eugene, OR, USA

2 Department of Child \& Family Studies, University of South Florida, Tampa, FL, USA

3 University of Wisconsin-Madison, Madison, WI, USA

\section{Introduction}

This paper presents a strategic plan for reducing the prevalence of concentrated disadvantage in the USA. Concentrated disadvantage consists of a tangle (Sampson 2009) of inter-related environmental and behavioral problems such as poverty, discrimination, unemployment, substance use, single parenting, and academic failure that result in intergenerational poverty and the development of multiple psychological, behavioral, and health problems often resulting in premature death (National Academy of Sciences 2019b).

4 Rollins School of Public Health, Emory University, Atlanta, GA, USA

5 Department of Psychology, University of South Carolina, Columbia, SC, USA

6 Human Development \& Family Studies, Iowa State University, Ames, IA, USA 
Over the past fifty years, the prevalence of such disadvantage has increased dramatically in the USA (Kristof and WuDunn 2020; Putnam 2016). Reversing this trend and thereby reducing the prevalence of these problems will require an unprecedented organization of our national resources over an indefinite period of time. We hope that this paper will contribute to such a nationwide effort.

The paper begins with a brief summary of what we know about the contextual conditions that undermine family wellbeing and the resulting patterns of family life that contribute to life-long intergenerational psychological, behavioral, and health problems. It then summarizes the extensive evidence regarding programs and policies that have proven benefit in preventing or ameliorating one or more aspects of disadvantage, as well as the research that is needed to translate existing knowledge into widespread success in reducing concentrated disadvantage and its sequelae. We then present a strategy for building a nationwide effort to strengthen family well-being with special attention to neighborhoods and communities of concentrated disadvantage.

\section{The State of America's Children and Families}

The well-being of America's families can be gauged by the quality of the contextual conditions that affect families and by the quality of family life itself. Even a brief summary of the evidence indicates that many families live in stressful social contexts and have high levels of family dysfunction.

\section{Contextual Conditions}

Among the harmful contextual conditions that have been verified by previous large-scale studies are family poverty, homelessness, contacts with the criminal justice system, discrimination, and the marketing of health-compromising behaviors in youth (e.g., unhealthful food and substances).

\section{Families'Economic Well-being}

According to the U.S. Census Bureau (Fontenot et al. 2018), 7,793,000 American families were living in poverty in 2017. According to the Organization for Economic Co-Operation and Development (OECD Family Database 2018), as of 2015, the USA had the third-highest rate of poverty among 35 developed countries (16.8\%).

The federally defined poverty level for a family of four is $\$ 25,100$ (Families USA 2018). As of 2018, $17 \%$ of children lived in homes with income below the poverty level, and $38.8 \%$ were in homes below $200 \%$ of the poverty level (Child Trends Databank 2019). A major reason for these rates of poverty is the high rate of single parenting. More than $58 \%$ of poor children live in single-mother families, and 8.3\% live in single-father families.

A meta-analysis by Stringhini et al. (2017) of 48 studies involving 1.7 million people showed that socioeconomic status was associated with higher rates of mortality even when the researchers controlled for 25 well-established risk factors for disease. Children raised in poverty had significantly greater risk of most psychological, behavioral, and health problems (Jarjoura et al. 2002; Matthews and Gallo 2011; Pampel et al. 2010) and shorter life expectancy (Galobardes et al. 2004, 2008; Miller et al. 2011).

Distinct from the effects of poverty, economic inequality is a risk factor for multiple psychological, behavioral, and health problems. Pickett and Wilkinson, as well as other investigators (Pickett and Pearl 2001; Pickett and Wilkinson 2010; Kaplan 2019), have shown that premature death, obesity, infant mortality, depression, social anxiety, property crimes, and homicide are greater in economically unequal countries. Many of these disparities in health are found among all but the very highest-earning segments of a population. The deleterious effects of inequality appear to be due to the fact that people living in economically unequal communities are more likely to have stressful interactions with people who are above or below them in the economic hierarchy (Pickett and Wilkinson 2015; Wilkinson and Pickett 2009).

\section{Homelessness}

According to a national system for estimating homelessness, there were about 58,000 homeless families with children on any given night in 2017 (National Alliance to End Homelessness 2020). Homeless children have more developmental delays, poorer academic development, and more physical illnesses and conditions, such as stunted growth, anemia, asthma, lead poisoning, and infectious diseases (Hart-Shegos 1999).

\section{Family Involvement with the Criminal Justice System}

The criminal justice system can have a devastating impact on families. The USA has the highest rate of incarceration in the world (Wagner and Walsh 2016), and there is a much higher rate of incarceration of black people, a result of disparities at every point in the criminal justice process, from arrest through sentencing (Alexander 2012). A survey of American adults indicated that $63 \%$ of black people indicated that a member of their family had been incarcerated; the rate was $42 \%$ for Whites and $48 \%$ for Hispanics (Enns et al. 2019).

Families with a parent in prison are likely to experience poverty, homelessness, and residential instability (Peterson et al. 2019). Parental imprisonment often contributes to children's behavior problems, depression, poor academic 
performance, and antisocial behavior (Parke and ClarkeStewart 2001; Peterson et al. 2019). Children may also experience trauma through involvement with the criminal justice system at other points (e.g., if they witness the arrest of a parent or before or during visits with a parent in prison or jail; Eddy and Poehlmann 2019).

\section{Discrimination}

Discrimination is widespread in the USA (National Public Radio, Robert Wood Johnson Foundation, \& Harvard T.H. Chan School of Public Health 2018). In addition to welldocumented effects on the health of individuals (Pascoe and Smart Richman 2009), discrimination affects family wellbeing due to discriminatory hiring and pay and residential segregation. However, the most damaging aspect of discrimination may simply be the frequent exposure to experiences that are threatening or aversive and that contribute to inflammatory disease (American Psychological Association 2016).

\section{Marketing of Substances that Undermine Children's Health}

The marketing of tobacco, alcohol, and unhealthful food and beverages harms families. Although the makers of these products often argue that their marketing is not to blame for underage use of tobacco and alcohol or childhood obesity, empirical research shows that marketers target children, their messages reach children, and these messages influence youths' purchases and consumption (Biglan 2004a; Nestle 2002; Pechmann et al. 2012). Moreover, the ready availability of illicit drugs in neighborhoods of concentrated disadvantage contributes to drug use disorders among both parents and children (Ford et al. 2017; Storr et al. 2004).

\section{Concentrated Disadvantage}

Each of the just-described conditions contributes to the development of psychological, behavioral, and health problems that undermine children's life chances and contribute to premature death. However, the risk of such outcomes is increased when multiple disadvantaging conditions are present. Evidence for this comes from studies showing that the greater number of adverse experiences that children have, the more likely that their behavioral and physical health will be affected (Anda et al. 2009, 1999; Felitti et al. 1998).

This underscores the necessity of targeting neighborhoods and communities of concentrated disadvantage if the nation is going to significantly reduce the number of children who are destined for multiple problems, impeded potential and premature death. A recent monograph by Acevedo-Garcia et al. documents the extent to which American communities have neighborhoods with extensive disadvantage (AcevedoGarcia et al. 2020).

\section{The Impact of these Conditions on Parents}

The just-described contextual conditions contribute to the undermining of effective parenting. Stressors such as poverty, economic inequality, and discrimination undermine parents' time, ability, and motivation to provide warm, responsive support of their children's development. Poverty, discrimination, unemployment, and homelessness also make depression more likely. Maternal depression is a risk factor for socio-emotional and cognitive delays in children (Bernard-Bonnin, Society, Health, \& Committee 2004). There is also evidence that neighborhoods that are low in socioeconomic status have higher rates of some types of substance use (Karriker-Jaffe 2013). And, according to the Substance Abuse and Mental Health Services Administration (SAMHSA), about $12.5 \%$ of children ( 8.7 million) live in homes where at least one parent has a substance use disorder (Lipari and Van Horn 2017). Parental substance use is associated with a higher likelihood of child abuse (Institute of Medicine \& National Research Council 2014) and later substance use by the child (Anda et al. 2002). Finally, as the proportion of marriageable men declines due to unemployment and poverty, family stability is undermined, and the rate of single parenting increases. Sawhill (2013) reported that, across ethnic groups, the rate of single parenting has increased in recent years among those without a college education.

\section{Disadvantage and the Quality of Schools}

Schools in high poverty neighborhoods and rural communities, generally have fewer resources than schools in more affluent areas, even though it is in high poverty areas that more resources are needed (Duncombe 2017). High poverty schools need more special education, more incentives for skilled teachers, and more effective supports for social and emotional learning. The absence of these resources is one of the reasons that students perform less well in high poverty communities (García and Weiss 2017).

\section{The Impact of Disadvantage on Children}

Evidence across a wide variety of sub-areas of behavioral science converge in a consilience about how stressful social conditions result in a "fast life" strategy where threatening environments make such a strategy more likely to result in successful reproduction (Wilson 2019), but frequently culminate in premature death. Figure 1 depicts the impact of a stressful social context on parents and schools and the subsequent impact of all of these conditions on child and adolescent development. The conditions increase the likelihood that parents will have multiple problems and that, as a result, families will have frequent coercive interactions (Dishion 


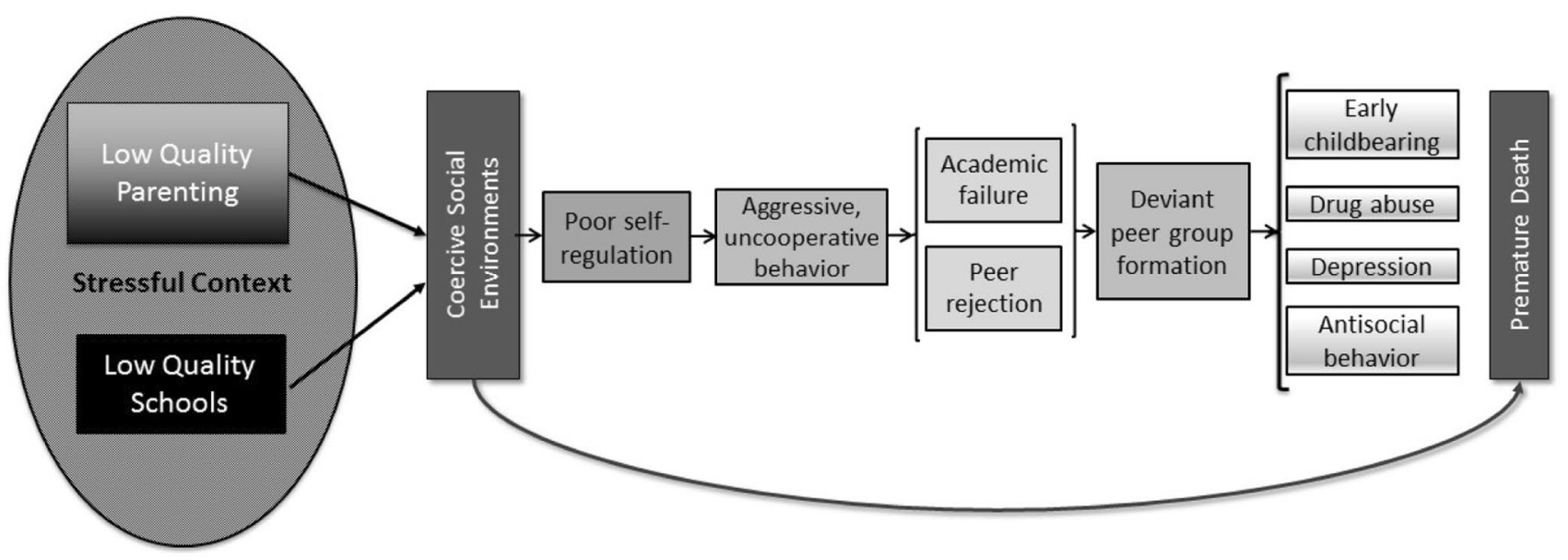

Fig. 1 "Fast" developmental pathway

and Snyder 2016). It is well established that coercive interactions in families contribute to children's failure to develop self-regulation and to the development of aggressive and uncooperative behavior that puts them on a trajectory to fail in school and be rejected by peers (Biglan et al. 2012; Dishion and Snyder 2016; Patterson et al. 1989). This rejection, in turn, leads to their joining with similarly rejected peers to form deviant peer groups. These groups become a training ground for the constellation of psychological and behavioral problems that include delinquency, substance use, risky sexual behavior, depression, and school dropout (DeBaryshe et al. 1993; Patterson et al. 1992, 1989).

This analysis is supported by research from a diversity of sub-disciplines (Biglan et al. in press). These include a wealth of evidence showing that multiple, interconnected problem behaviors result from a common set of adverse environmental conditions (Biglan et al. 2004). It is also supported by evolutionary analyses of the expression of fast life strategies that appear to have survival value in a dangerous environment (Ellis and Bjorklund 2012; Ellis et al. 2012; Wilson 2019). It is shown by the evidence of epigenetic changes that make these strategies more likely (Bergen et al. 2012). The analysis is also consistent with social psychological research contrasting the development of materialistic vs. prosocial values and the impact of threat on materialism and the association of materialism with diminished wellbeing (Kasser 2016). Finally, there is clinical psychological research showing the benefits to human well-being of psychological flexibility, which is a pragmatic way of living that involves living intentionally according to one's values, a life strategy that benefits the individual and those around that individual (Hayes 2019).

In addition to family influences, the quality of schools affects this developmental trajectory. As noted above, schools in high poverty neighborhoods and communities have higher rates of punitive practices and fewer resources for preventing the development of problem behavior (American Psychological Association, n.d.).

There is one other point to be made about this developmental trajectory because it is so important for redirecting the expenditure of resources in our healthcare system. The U.S. per capita cost of healthcare is at least twice that of most other developed nations even though we lag behind these nations in health and longevity (Biglan 2019). A major yet frequently overlooked reason for these disparities is that ill health and premature death are made more likely by stressful social interactions in childhood (Miller et al. 2011). Redirecting some of our healthcare expenditures to the prevention of stressful social relations in childhood is likely to make a bigger contribution to American's health than any advance in the treatment of chronic disease (Biglan 2020a).

When coupled with evidence from prevention research, these findings suggest a unifying framework about the kind of environments that are needed to nurture successful development (Biglan 2015a; Biglan et al. 2012). Figure 2 depicts the way in which nurturing conditions contribute to the development of prosocial behavior. By prosocial behavior, we refer to constellation of behaviors that contribute to not only the individual well-being, but the well-being of those around the person. These include caring, compassion, and an orientation toward helping others (Kasser 2011). They also include the development of a wide range of academic and social skills, as well as skill in art, music, and science. The evidence indicates that the development of prosocial behavior is promoted by environments that (a) minimize socially toxic coercive interactions, (b) richly reinforce all types of prosocial behavior, (c) limit both opportunities for problem behavior (such as unsupervised involvement with highrisk peers) and influences toward problem behavior such as the marketing of tobacco and alcohol, and (d) promote 


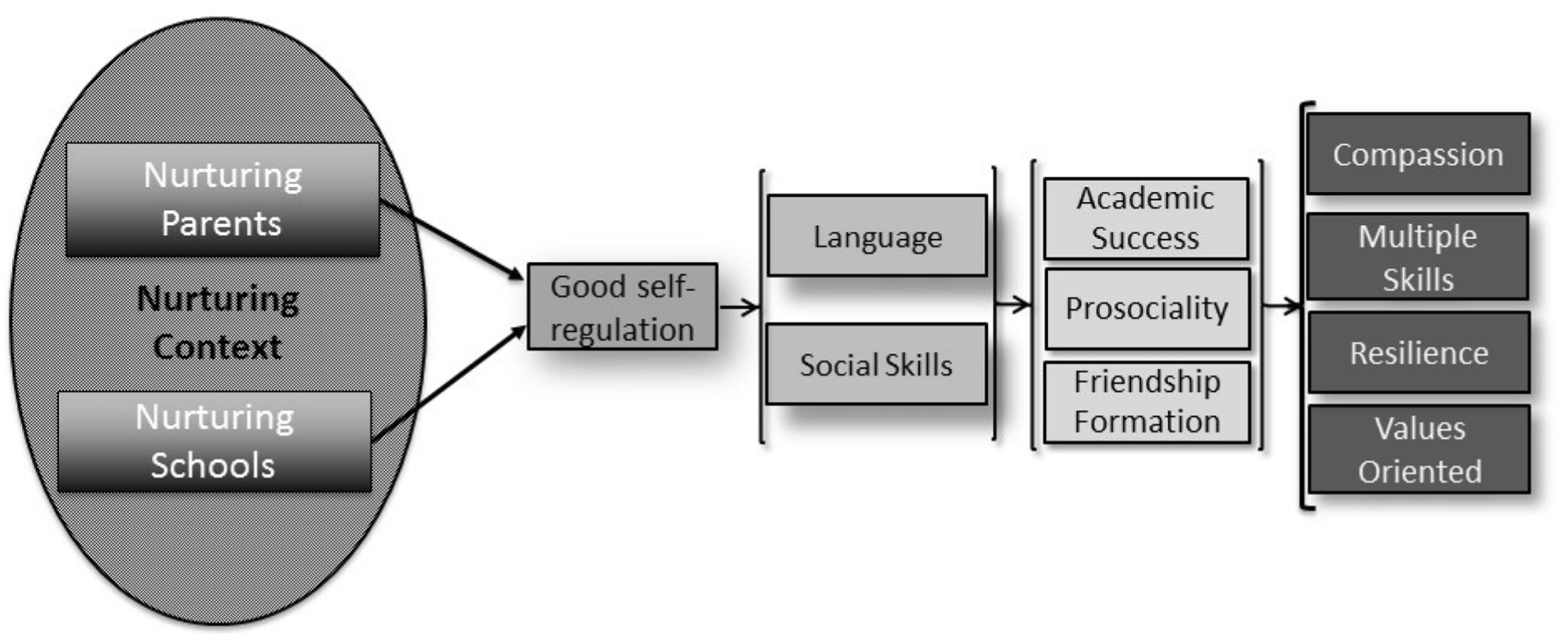

Fig. 2 Developmental under optimal conditions

psychological flexibility, which is a values focused, mindful, and pragmatic way of living. Thus, in the next section, we summarize the research suggesting that this problematic fast life trajectory can be prevented through the promotion of these nurturing conditions. The figure also indicates that we need to be concerned not only with the proximal family and school influences on development but on the neighborhood and community conditions that affect families and schools and often directly affect the child.

\section{Modifying the Contextual Conditions That Harm Families}

As just suggested, focusing only on the proximal family and school influences on development is insufficient. We need to be concerned with multiple systems that can improve family well-being. In this section, we review evidence on interventions designed to affect the contextual conditions that we described above.

\section{Improving Family Economic Well-Being}

In addressing family poverty, we rely on a recent NAM report, A Roadmap for Reducing Child Poverty (NASEM 2019a), which thoroughly reviewed the evidence on the impact of poverty on children and the policies that have been shown to reduce it. The report identified ten policies or programs shown to reduce family poverty. Contextual factors that have been instrumental in understanding family wellbeing involve many systems. We focus on policies below that could have a fundamental impact on these contextual factors. Four policies both increase income and promote employment. The report deemed promotion of employment to be as valuable as increasing income because employment raises the probability that a family will continue to prosper over time. This view is consistent with our priorities in using a multi-level and systemic approach to improving family well-being.

\section{The Earned Income Tax Credit (EITC)}

This policy supplements low paid workers' income by providing a tax credit on income they have earned. For example, people receive a refund of money previously withheld from their taxes. The credit is refundable in the sense that a worker may receive more money for their work than they would have had to pay in taxes. Research on the EITC shows it reduces poverty, increases workforce participation (Nichols and Rothstein 2016), and increases the long-term health of family members. Markowitz et al. (2017) found an association of higher tax credits with higher birth weights and longer gestation periods. Unfortunately, 22 states do not offer a state EITC and an additional six states have a nonrefundable EITC (Tax Policy Center, nd.). A nonrefundable EITC can only offset state income taxes, so the benefit is limited for low-income families with little taxable income. Also, many families who are eligible for federal and state EITCs do not apply for them, thus indicating a need to increase education and access to these opportunities.

\section{Federal Childcare Subsidies}

These subsidies impact family income, and at the same time, they increase workforce participation because they enable family members to work who might otherwise be providing childcare. The NAM report estimated that the average 
annual cost for childcare for a young child (age 2 through 5 ) is $\$ 8,600$.

\section{Increasing the Minimum Wage}

The current federal minimum wage is $\$ 7.25$ an hour, although 30 states and the District of Columbia have higher minimum wages. The NAM report concluded that raising the wage could reduce the availability of jobs in some places if employers reduce their workforce in response, but also cited evidence that a higher minimum wage helps lift families out of poverty. An analysis by the Robert Wood Johnson Foundation (2018) concluded that minimum wage increases are associated with improved health. Specifically, adult women who became pregnant and experienced an increase in the minimum wage had a reduced likelihood of smoking and fewer low birth weight babies. Increases in state-level minimum wages are associated with decreased infant mortality, suicide rates, and heart disease death rates (Kaufman et al. 2020; Komro et al. 2016; Van Dyke, Komro, Shah et al. 2018).

\section{Effective Workforce Development Programs}

At least two workforce development programs have been shown to increase employment and earnings for poor unemployed or underemployed workers.

WorkAdvance (Schaberg 2017) was reviewed in the NAM report. This program works with potential employers to identify the skills they need and then trains workers on those skills. Four workforce development organizations ran randomized trials evaluating the program, and though not all replicated effects, the program was shown to increase employment, earnings, and job satisfaction.

In addition, the Arnold Foundation, which funds and monitors results of randomized controlled trials evaluating government-funded interventions, reported that a randomized trial of Quest, a job training program for low-income individuals, showed that it increased recipients' annual income $20 \%$ more than the control group over a nine-year follow-up period (Straight Talk on Evidence 2019). Like WorkAdvance, Quest works with employers to identify skill sets that companies need and provides training in those skills.

Based on this evidence, it appears that workforce-training programs focused on training for job skills that are in demand should be one component of improving family income. Additional randomized controlled trials of such programs should take place and should include ongoing monitoring of their impact.

\section{Expanding Housing Vouchers}

The National Academy of Medicine report also examined the impact of a set of policies that would directly increase family income. One is housing vouchers. The federal government provides vouchers to families with very low incomes to subsidize rent, thus reducing expenditures and often enabling moves to better neighborhoods. A randomized trial of the impact of housing vouchers showed that they contributed to lower levels of obesity and depression (Ludwig et al. 2011) and increased later earnings of those who moved to more affluent neighborhoods before the age of 13 (Chetty et al. 2016). The NAM report (NASEM 2019b) indicated that increasing housing vouchers could result in moving $3 \%$ of children who currently live in poverty out of poverty.

\section{Expanding the Supplemental Nutrition Assistance Program (SNAP)}

The National Academy committee on poverty reduction also concluded that an increase in the number of families receiving assistance would contribute to reducing the proportion of children living in poverty by $2.3 \%$.

\section{A $\$ 3000$ Per-child Annual Allowance}

The committee also estimated that this supplement to the income of poor families could reduce the number of children living in poverty by $5.3 \%$.

Note that while the NAM report focused primarily on how these policies would increase family income and labor force participation, most have also improved health and wellbeing. For example, the report notes that the EITC improves children's educational and health outcomes.

\section{Reducing Discrimination}

There is evidence that when people work together, each contributing to the group's success, prejudice diminishes. The most extensive research on this strategy involves cooperative learning procedures in schools, wherein small groups of students learn to work toward a common goal. This strategy has been shown to reduce prejudice and bullying (Van Ryzin and Roseth 2018a). Paluck and Green (2009) note that very little of this research has been done in real-world settings.

Given the extent of discrimination in the USA, its impact on public health, and the size of the workforce, it is imperative that foundations and the NIH fund research to identify more effective ways to reduce prejudice in schools, work settings, and neighborhoods and communities. 


\section{Evolving a Criminal Justice System to Enhance Family Well-Being}

Jurisdictions across the USA are beginning to recognize and address the harms that criminal justice involvement can cause in families. For example, some efforts are underway to reduce sentence length, eliminate incarceration, and use alternative sentences (e.g., enhanced community supervision) for certain nonviolent crimes. Yet the country can do much more. The USA has not only a far higher rate of incarceration than other developed countries, it also has a much higher recidivism rate (Fazel and Wolf 2015).

Comprehensive reform of the criminal justice system will require that its leaders make their primary goal a reduction in the incidence of crime. The pursuit of this goal will require a bigger investment in prevention, which, in turn, will require the system to become more involved in and supportive of the other sectors of society, including schools, family services, and healthcare. It will also require the adoption of evidence-based practices that can reduce recidivism. Among the reforms that are likely to remedy this problem are the following.

\section{Shutting Off the School-to-Prison Pipeline}

Punitive practices in schools, such as zero-tolerance policies, often escalate suspensions and expulsions. This results in children's separation from school, extra-curricular activities, and peers and increases the likelihood of further offending as well as dropping out of school (American Psychological Association-Zero Tolerance Task Force 2008; Insley 2001; Martinez 2009; Mitchell 2014). Moreover, school and justice policies that bring together at-risk youth amplify the development of antisocial behavior (Dishion et al. 2006). These practices need to be replaced with evidence-based therapeutic interventions (Lipsey 1992; Lipsey et al. 2010).

\section{Reduce the Harmful Effects of the System on Families}

Involvement of parents in the criminal justice system can be traumatizing to their children at the same time that it reduces family income and the availability of a parent (Peterson et al. 2019). Promising evidence points to enhanced family relationships through interventions such as parenting skills training, well-managed visitations, and improved communications (Dallaire et al. 2015). However, the evidence is not sufficient to justify widespread implementation. Further research on how to reduce the harm to families affected by incarceration should be a high priority.

In addition, immigration policy is currently doing substantial harm to children and families. The current highly punitive policies need to be examined in terms of the harm that they do. Policy reform must start with the goal of enhancing rather than undermining family well-being-a reform which is unlikely under the current administration.

\section{Marketing of Unhealthful Products}

As noted above, the marketing of tobacco, alcohol, and unhealthful food harms children's health and undermines parents' efforts to protect it. Some progress is being made in regulating cigarette marketing because the evidence is so clear that such marketing contributes to underage smoking (Biglan 2004b) and, ultimately, to the deaths of about a third of smokers (Centers for Disease Control and Prevention 1996). Similarly, the marketing of alcohol has been shown to increase underage drinking (Sargent and Babor 2020). Food marketing needs similar research. To the extent that research helps to determine whether marketing is a causal influence on alcohol or unhealthful food consumption, governments should regulate such marketing in the same way it regulates tobacco marketing.

It is also clear that taxing tobacco and alcohol significantly reduces the proportion of young people who smoke or drink (Komro et al. 2013). And the evidence is beginning to emerge that taxation on sugar-sweetened beverages, can reduce the consumption of these products (Redondo et al. 2018).

The harm that consumption of tobacco, alcohol, and unhealthful food does to children is substantial. This problem could be reduced if federal and state governments implement inflation-adjustable taxes on alcohol and unhealthful food and that those taxes are commensurate with taxes on tobacco products.

\section{A Wealth of Evidence-Based Family and School Interventions}

In this section, we present a brief overview of the family and school interventions that have been shown to prevent problem development in youth. The evidence documents numerous family and school interventions that make these environments more nurturing. While it is true that addressing the above-described contextual conditions is likely to improve family well-being significantly, it is unlikely that reducing problems like poverty and discrimination will ensure that every family and school adopt the most effective ways of nurturing children's development (Van Ryzin et al. 2018). Interventions are needed at both levels.

\section{Family Interventions}

Research over the past thirty years has identified a broad array of family interventions that are available across the developmental spectrum. These interventions can reduce coercive interactions, promote parental skills in 
reinforcing prosocial behavior, set limits on risky behavior, and promote resilience in the face of challenges that stressful environments can pose. The strategies focus on two main areas: (1) family promotion of children's social, emotional, and behavioral well-being and (2) family promotion of children's healthy lifestyle behaviors to lower risk of obesity and other chronic disease conditions. This section briefly summarizes progress in each area and discusses what strategies can help achieve broad positive parenting and family support in society.

\section{Promotion of Children's Social, Emotional, and Behavioral Well-Being}

Over five decades, clinical and prevention professionals have developed a broad array of parenting and family support programs to foster social, emotional, and behavioral well-being of children. Hundreds of studies document the benefits of such programs for families and children from infancy through adolescence. Parenting and family support programming, if broadly implemented, has the potential to impact child mental health, child abuse, academic failure, bullying, antisocial or violent behavior, substance misuse, obesity, sexually transmitted disease in adolescence, teen parenthood. These programs increase positive and nurturing parent-child interactions, kindness, cooperation in peer interactions, and safe family environments (Biglan et al. 2012; Leslie et al. 2016; National Research Council \& Institute of Medicine 2009; Prinz 2012; Van Ryzin et al. 2016).

Many of these programs have common elements (Prinz 2012), including the following:

- Adopting a positive frame: no matter the circumstances, effective programs convey an optimistic and positive approach to each family.

- Action focus: parents actually do things instead of simply talking with a staff member.

- Problem-solving orientation: emphasis on solving current problems, not on casting blame.

- Specific, concrete, and practical parenting strategies: programs offer menus of strategies to address parenting challenges.

- Collaborative goal setting: parents and staff members collaborate to set programmatic goals for each family.

- Consultative rather than prescriptive attitude: programs favor providing useful consultation to parents without giving them orders.

Such programs reflect a well-honed set of parenting practices that are adaptable to children's ages and that offer parents many ways to foster nurturance, such as.
- Giving rules and instructions to children before situations begin.

- Paying frequent attention to positive behaviors.

- Providing supportive prompts, coaching, and correction.

- Setting clear limits and boundaries.

- Ignoring harmless but annoying behaviors so children don't get an "audience" for these.

- Recognizing and encouraging behaviors that are the opposite of any identified problem behaviors.

- Rearranging situations so that positive behaviors result in enjoyable activities.

- Expressing affection and caring frequently.

- Developing effective ways of solving daily and recurring problems.

- Envisioning the future and setting specific and attainable goals.

\section{Family Promotion of Children's Healthy Lifestyle Behaviors}

Families can positively influence youth health behaviors by providing a warm and supportive setting for learning, growth, and development (Kitzman-Ulrich et al. 2010; Wilson et al. 2017). It is increasingly apparent that positive parent-child communication is fundamental in promoting healthy behaviors in children. Specifically, a supportive family climate has a positive association with adolescent health behaviors and healthy weight status (Berge et al. 2013; Halliday et al. 2013; St. George et al. 2013; Wilson and Sweeney 2018). Research shows that higher levels of family functioning (defined as communication, joint problem solving, closeness, and appropriate behavioral control) are related to healthier body mass index, nutrition, and physical activity among adolescents. Haines and colleagues (Haines et al. 2016) found similar results. They discovered relationships between higher family functioning, lower obesity risk, and less sedentary behavior. Other evidence indicates that improving family climate through positive interventions reduces deleterious effects of unsupportive parenting on youth weight-related outcomes, with benefits that can be detected nearly 15 years later (Brody et al. 2016; Wilson et al. 2017).

Family programs that improve children's self-regulation also promote healthy lifestyles from early childhood through adolescence. For example, self-monitoring, which involves prompting families to keep a record of a specified behavior (e.g., in an electronic or written diary), is one of the most effective strategies for eliciting changes in diet and physical activity (Michie et al. 2009). Another common strategy is prompting specific goal setting. This includes details such as the frequency, intensity, or duration of behavior, as well as specifying when, where, and how the child plans to achieve the goal (Gollwitzer 1999). Action planning, including encouraging families 
to identify potential barriers to performing a behavior and planning supportive ways to overcome them, is another often-used technique for promoting healthy lifestyle changes (Ayotte et al. 2010; Bandura 2004). These behavior-change strategies have been increasing in family contexts to promote health-related behaviors among lowincome and ethnic minority populations.

Another approach for promoting healthy behaviors among youth focuses on supporting their autonomy, rather than telling them what they should do. Motivational Interviewing (MI) is designed to increase motivation for behavior change by listening to the child about their concerns and joining them around their personal desires to change their health or weight (Miller and Rose 2009). Rather than providing advice or urging specific actions, clinicians and parents use this strategy to elicit the motivation to change from individuals themselves using strategies through reflective listening and shared decision-making. The counselor or parent can then provide the child (or adolescent) with specific behavioral skills, including identifying goals, creating an action plan, anticipating potential barriers, and monitoring children's health behaviors (Resnicow and McMaster 2012). Ample evidence shows MI is an effective strategy when coupled with behavioral skills training for reducing weight problems and obesity (for a review, see Armstrong et al. 2011) and for helping parents facilitate weight loss in their overweight children (Resnicow et al. 2015; Spear et al. 2007).

In the MI framework, shared decision-making and autonomy support are critical skills for parents as youth transition from childhood to adolescence (Ryan et al. 2006). Shared decision-making involves parents and children making decisions together in a way that facilitates sharing in ownership over plans. This encourages motivation for and enjoyment of healthy behaviors (Ryan et al. 2006). Studies have demonstrated positive associations between parental autonomy support and adolescent intrinsic motivation on improving healthy lifestyle-related behaviors and adhering to weight-loss treatment (Mâsse et al. 2014). Parents can also use this strategy to model problem solving and troubleshooting of barriers.

Research has shown that these behavioral and motivational approaches are effective for improving health behaviors from early childhood through adolescence (Kahan et al. 2018; St. George et al. 2013; Wilson and Sweeney 2018; Wilson et al. 2017). However, in the case of these health behavior interventions, a gap between research and practice exists that limits the implementation of evidence-based interventions outside of research programs. This gap exists because we have not yet developed effective strategies for getting nonresearch settings to adopt these strategies.

\section{Treatment of Parental Substance Abuse}

Given the deleterious effects of parental substance use on children, interventions to address parental substance use are needed. The evidence for the value for children of treating parental substance use is currently limited. Calhoun et al. (2015) reviewed four randomized trials of the impact of treating parental substance use on children. Each of these studies provided some evidence that parental treatment could benefit children, either by reducing the likelihood of the children's substance use or by improving children's psychological or behavioral functioning.

\section{Reducing Family Violence}

Research on evidence-based methods for reducing family violence indicates promising effects of behavioral interventions. Although much more research is required for strong recommendations about how to prevent child maltreatment, studies have shown positive effects of parenting programs that reduce risk factors such as parental depression and stress, parents' inappropriate attitudes toward child-rearing, abusive parenting behaviors, insufficient parenting skills, and minimal knowledge about child development (Chen and Chan 2016).

Recent research on domestic violence interventions also indicates promising new efforts using cognitive-behavioral interventions. An intervention based on Acceptance and Commitment Therapy is now being used in the state of Iowa for all individuals convicted of domestic violence. The intervention joins an abusing partner around their own prosocial goals and helps them learn to step back from anger-inducing thoughts, and feelings in a self-compassionate way. In this context, they become better able to control anger and develop more nurturing ways of interacting with their family members. Research on the program shows preliminary evidence that it is effective in reducing repeat domestic assault, in both community corrections and incarcerated populations (Berta and Zarling 2019; Zarling et al. 2017).

\section{Need for Broad Population Reach}

Evidence-based family interventions are essential but not sufficient for a successful impact on the well-being of children and their families. Broad population reach is critical as well. Reaching one family at a time (e.g., home visitation programs) has utility but does not preclude the use of collective and cost-efficient strategies to provide parenting and family support for large numbers of families. Critical to population reach are multiple access points for programming, an array of delivery modalities including media, the involvement of personnel from several service sectors, de-stigmatized programming capitalizing on a range of 
intervention intensities, and recognition of how to take into account major social determinants of health (Kaplan 2019; Prinz 2019).

\section{School Interventions}

Substantial progress has also been made on school interventions that promote prosocial behavior and prevent the development of multiple problems. These programs have in common a focus on helping schools to replace punitive discipline practices with practices that promote prosocial behavior. Here we briefly describe four programs that have proven benefit.

\section{Positive Behavioral Interventions and Supports}

PBIS is a schoolwide system for promoting prosocial behavior. A team of staff members establishes and monitors PBIS implementation. They establish a small number of clear rules for appropriate behavior. Common rules are Be Responsible, Be Respectful, and Be Safe. Students are then taught examples of behavior consistent with these rules in all of the venues of the school (classrooms, hallways, playground, buses). A system for increasing praise and rewards for appropriate behavior is put in place throughout the school. The PBIS system monitors disruptive or inappropriate behavior throughout the school and uses the data to pinpoint settings or individuals with high rates of inappropriate behavior. This enables the PBIS team to put in place more intensive interventions for particular students or settings in the school.

Bradshaw et al. (2012) reported a group randomized trial of the impact of positive behavior intervention and support and 37 elementary schools. They found significant reductions in behavior and concentration problems and improved social-emotional functioning, and prosocial behavior. Children in PBIS schools were $33 \%$ less likely to be referred to the office for inappropriate behavior. PBS is now in more than 25,000 schools throughout the nation.

\section{Positive Action}

This is a program that teaches students to engage in positive actions throughout the school. Washburn et al. (Washburn et al. 2011) reported on three randomized trials evaluating Positive Action in elementary schools. In all three studies, students who were randomized to the positive action intervention showed smaller declines in positive actions than those in controls. The program appears to have arrested the typical decline in positive actions that is seen as students enter early adolescence. The randomized trial conducted in 14 Chicago elementary schools showed that the students receiving Positive Action had significantly more positive affect and life satisfaction, and significantly lower levels of depression and anxiety (Lewis 2013a, 2013b).

\section{Cooperative Learning}

Cooperative learning was originally developed as a method of increasing student learning, especially among students who were performing poorly. This strategy involves having small teams of students work together in ways that require each student to make a contribution to the group's product. Numerous studies have shown the benefit of cooperative learning in increasing academic success (Roseth et al. 2008). It has also shown a clear benefit in reducing intergroup prejudice (Pettigrew and Tropp 2008). Recently, a randomized trial of cooperative learning in middle schools has shown that the program significantly reduced bullying and victimization and that students in the cooperative learning condition reported less stress, fewer emotional problems, and less use of alcohol and tobacco (Van Ryzin and Roseth 2018b).

\section{The Good Behavior Game}

Like cooperative learning, the good behavior game involves small teams of students working together cooperatively. Teams that meet the criteria for appropriate behavior receive rewards such as extra time for recess. Extensive research over a period of 40 years has shown that the good behavior game significantly reduces disruptive behavior (Embry 2002). A randomized trial of the benefit of the good behavior game among students in early elementary school in Baltimore showed that students who played the game were significantly less likely to smoke or be arrested by middle school and that by young adulthood they were significantly more likely to graduate high school and attend college and significantly less likely to have problems with substance abuse, antisocial behavior, or suicidality (Kellam et al. 2014). The Paxis Institute developed a version of the good behavior game that combines it with a set of simple behavior influence techniques called kernels. That version of the game has generally replicated the benefits of the program that were shown in previous studies (Johannsson, Biglan, \& Embry, under revision). At this writing, more than 40,000 teachers have been trained in the implementation of this version of the game.

\section{Collaboration Between Families and Schools}

There is also evidence of the benefit of increasing collaboration between families and schools. Jeynes (2012) conducted a meta-analysis of the impact of a variety of parental involvement programs on academic success and found they increased the performance of students of all ages. Similarly, Sheridan, Smith, Moorman Kim, Beretvas, and Park (2019) 
conducted a meta-analysis of 117 studies on the impact of various types of family-school collaboration on students' social-emotional functioning and found significantly better social-behavioral competence and mental health among students of all ages; effects were strongest for African American children. The components of collaboration that made a difference included two-way communication between parents and teachers and trust between parents and teachers. Also important was school provision of enrichment activities for the home, parents volunteering in the classroom, and specific help to parents on how to model and reinforce desirable behavior.

Despite the benefits of family-school collaboration, the collaborative practices Sheridan et al. (2019) identified remain largely aspirational in typical school environments (Garbacz et al. 2017). Perpetuating the gap between research and practice is a lack of trust families and educators have for each other. Mistrust has intensified over time through certain practices, such as the disproportionate use of discipline (Townsend 2000). To promote family well-being, evidence-based family-school systems and practices (Sheridan et al. 2019) should be aligned and integrated within existing school programs and initiatives (Garbacz 2020). Such alignment and integration will provide the necessary context, through two-way communication, culturally sensitive practices, and family-centered services for parents and educators to build the skills and relationships necessary to strengthen families and support children. To advance this line of work, research is needed that examines the impact of strategies for promoting collaboration on (a) the level of parent-teacher collaboration; (b) the impact on teachers' attitudes and beliefs about parents and collaboration with them, and teacher burnout/morale; and (c) factors that explain the impact of a strategy on an outcome. In addition, an examination of the implementation process should consider alignment and integration in school and community systems; parent, youth, and teacher characteristics and experiences; the school infrastructure; and the external environment (Feldstein and Glasgow 2008).

\section{Needed Research}

This brief review of family and school interventions documents the availability of numerous programs that can contribute to the well-being of families and the prosocial development of children. At the same time, additional research is needed if we are going to translate this body of knowledge into a widespread benefit. Continued investment in strengthening these interventions is likely to improve their effectiveness. Although there is evidence of the benefit of family and school interventions for poor and minority populations, further research on reaching and affecting this population is needed (Van Ryzin et al. 2015). Moreover, research on combining interventions at multiple levels and on how to get these interventions widely and effectively implemented will enhance our ability to make them available to neighborhoods and communities of concentrated disadvantage.

\section{A Strategic Plan for Strengthening Child and Family Well-being}

The evidence presented thus far establishes three things. First, a large proportion of children and families are living in circumstances that undermine their well-being. Indeed, over the past fifty years, conditions for families have deteriorated in the U.S. (Kristof and WuDunn 2020; Putnam 2016), and we have fallen behind other economically developed nations (UNICEF 2007).

Second, those at greatest risk for future psychological, behavioral, and health problems are living in neighborhoods or communities of concentrated disadvantage. Our impact on child and family well-being will be limited if we do not focus policies to alleviate structural barriers to well-being and how to further provide resources and assist these neighborhoods and communities.

Third, there is ample evidence that changes in public policy and the wider implementation of family, school, and community interventions can prevent or ameliorate many of the factors that undermine development. In principle, we have the knowledge needed to significantly improve wellbeing in American communities.

We are, however, a long way from effectively addressing family well-being. Despite the availability of policies and programs that could increase the number of families that are thriving, there appears to be no systematic plan for steadily improving well-being.

The National Academy's 2019 report Fostering Healthy Mental, Emotional, and Behavioral Development in Children and Youth (NASEM 2019b) called for a decade-long effort focused on promoting healthy development. The report further called attention to the fact that seven other Academy reports had advocated for greater attention to the problems of poverty and concentrated disadvantage because these conditions constitute the greatest obstacle to successful development. In keeping with this focus, the remainder of this paper presents a strategic plan for how we might create an unprecedented effort to reduce concentrated disadvantage and thereby increase the proportion of families that support the successful development of children and adolescents.

There are various sectors and policymaking bodies that are trying to address the challenges to family well-being. However, there is not a comprehensive and sufficiently cogent plan to fully impact family well-being in the U.S. For this reason, this strategic plan is addressed primarily to the key policymaking bodies, leaders in business, NGOs, and 
foundations, child and family advocates, other key opinion leaders, and consumer groups.

The proposed goals for this effort would be as follows.

1. Increase the proportion of American families that meet an empirically defensible public health standard of wellbeing.

2. Identify, monitor, and reduce the number of neighborhoods and communities of concentrated disadvantage.

3. Promote the adoption and implementation of policies and programs that advantage families.

4. Increase the amount of research relevant to reducing family disadvantage. This would include research on

a. Establishing a national standard for family wellbeing in the form of an index of family well-being.

b. Experimentally evaluating comprehensive strategies for reducing disadvantage in neighborhoods of concentrated disadvantage.

There are two facets of our plan for furthering these goals. The first concerns organizing an unprecedented coalition of all sectors of society to make increasing the well-being of American families a national priority along the lines of what the NASEM report on the promotion of mental, emotional, and behavioral health called for. The second is the creation of research agenda that would advance family well-being, especially in neighborhoods and communities of concentrated disadvantage.

\section{Building a Coalition of the Key Sectors of Society}

Every sector of society has a role to play in reversing the deterioration of family well-being that has occurred over the past 50 years (Putnam 2016). In each sector we need to identify practices that undermine family well-being and those that enhance well-being. The foundational value for this effort is a commitment to ensuring the well-being of every person. It is only when a growing number of people do so that we will have the support for the norms and public policies that select beneficial practices and diminish harmful ones (Biglan 2020a).

We envision a process in which each sector is prompted to examine whether its practices are contributing to the reduction of concentrated disadvantage. In particular, it would look for ways in which the sector undermines well-being and the degree to which it makes use of evidence-based policies and programs that enhance well-being.

\section{Higher Education}

Higher education is critical to a nationwide effort to reduce concentrated disadvantage. Over the past forty years, a consilience has emerged in the human sciences regarding the conditions that people need to thrive and those that contribute to the development of psychological and behavioral problems and premature death (Biglan 2015, 2020a, b, c, d, e, f, g; Biglan and Embry 2013; Biglan et al. 2012; Biglan et al. 2019; Catalano et al. 2002; Dishion and Snyder 2014; Hawkins et al. 2014; Institute of Medicine 2009; Kasse 2011, 2016; Miller et al. 2011; NASEM 2019a, 2019b; National Research Council \& institute of Medicine 2009; Wilson et al. 2014). The 2009 report of the National Academy of Medicine summarized the evidence this way: "The scientific foundation has been created for the nation to begin to create a society in which young people arrive at adulthood with the skills, interests, assets, and health habits needed to live healthy, happy, and productive lives in caring relationships with others."

The research and training functions of our universities need to further develop strategies for translating what we know into effective interventions for disadvantaged families. According to the Society for Prevention Research, there are only seven Ph.D. programs in prevention science in the USA; there are seven Masters level programs (Society for Prevention Research 2018). Increasing their numbers is a first step in advancing effective prevention. Many other areas of the human sciences have a role to play in strengthening supports for family well-being. Every university should be encouraged to examine how well it is preparing the scientists and practitioners that are needed to address the needs of families.

Higher education can also affect the trajectory of children living in disadvantaged communities. They can work with those communities to increase the number of children who attend college. They can reduce the costs of higher education for disadvantaged children.

\section{Healthcare}

Our healthcare system needs to shift from a primary emphasis on treating diseases once they develop to preventing them in the first place. Here is just one example. There is an epidemic of childhood obesity in the USA and with it, a growing tendency for children to develop what used to be called adult-onset diabetes (U.S. Department of Health and Human Services 2018). A common practice among pediatricians is to screen children for obesity and counsel them and their parents (Perrin et al. 2007). However, there is no evidence that intervention with an already obese child affects their trajectory (Homer 2009). On the other hand, there is extensive evidence about the impact of food industry marketing on obesity and of the benefit of increased taxation on unhealthful food (Biglan 2020b). Restricting marketing and increasing the price of these foods are the practices that are needed. The same is true for the prevention of smoking and alcohol 
use (Biglan 2020c; Pechmann et al. 2012). Strengthening the ability of the public health segment of the healthcare system to practice population health promotion will have a significant impact in reducing the incidence of a wide variety of disease that we currently wait to treat. The role of the public health sector in addressing the Coronavirus epidemic may increase support for public health. In any case, this is the sector of the healthcare system that can lead the reforms that are needed.

\section{Business}

Recent developments in business include a movement to evaluate business practices in terms of their contribution not just to investors, but to employees, customers, suppliers, and the society as whole. The Business Roundtable recently embraced these values and the B Corp and Conscious Capitalism (Business Roundtable, n.d.; B Corporation, n.d.; Mackey and Sisodia 2014) movements have been promoting them for some time. Concrete steps that businesses can take include: (a) identifying and eliminating practices that harm, such as the marketing of harmful products (Biglan 2020b; 2020c; 2020d; 2020e; 2020f; 2020g); (b) assessing the well-being of employees, customers, and the communities that they operate in; and (c) adopting practices that steadily increase family income and supports for child-rearing such as high quality day care and paid parental leave. A company that truly embraces the goal of ensuring that its employees are thriving, would strive to ensure that their wages are above the poverty level. The allies in reform of business norms and practices are the leaders of the Conscious Capitalism and B Corp movements.

\section{Criminal Justice}

As discussed above, the criminal justice system can reduce harm to families by reducing the use of imprisonment and investing more heavily in rehabilitation and the prevention of juvenile crime. There are numerous organizations working to reform this system (Kerman, n.d.). They are natural allies in any effort to reduce family disadvantage.

\section{Family Services}

We reviewed the array of family interventions that are available to help families reduce conflict and promote prosocial skills. Every community has such services. They are increasingly guided by empirical evidence about effective practice. We need to encourage the transition from reactive intervention to instances of child abuse and neglect to a system of family check-ups and provision of support that prevents problems from developing.

\section{Schools}

We also described some of the school-based programs that are available to schools. Here too the challenge is to increase the proportion of schools that have the resources to make use of these programs.

\section{Why a Coalition is Needed}

Both the reform and the effectiveness of each of these sectors will be enhanced if organizations working in any given sector form a coalition with other sectors (Biglan 2020a) There are three reasons. First, the explicit embrace of the goal of enhancing population well-being by any give sector will build support for this goal in other sectors. For example, when people in criminal justice speak of reducing the incidence of juvenile crime and increasing the prevalence of prosocial youth it encourages those in other sectors to think in terms of the well-being of the entire population they serve rather than only those who seek or are remanded to intervention.

Second, progress in any sector makes the job easier for any other sector. For example, to the extent that criminal justice and family services improve their support of families, schools will have fewer students who lack self-regulation, engage in disruptive behavior, and fail academically. Conversely, to the extent that schools are nurturing prosocial behavior, they will prevent crime.

The third reason a coalition is needed is so that, speaking with one voice, the organizations in each of these sectors can look beyond a narrow focus on the problems each addresses and work to address contextual conditions that contribute to most psychological and behavioral problems as well as poor health. Our systems for dealing with human problems have naturally evolved out of the need to address an emergent problem-a crime, an injury, and illness. As such they are reactive. However, the evidence presented above documents the impact of poverty, discrimination, homelessness, and concentrated disadvantage have on the entire range of problems. Each sector has a stake in reducing these problems. Speaking with one voice about the need to address these problems would contribute to greater support for the policies needed to address them.

Coalition building will need to proceed at the local, state, and national levels. Increasingly community interventions are making use of the collective impact model to bring the sectors of the community together around a shared agenda (Kania and Karmer 2011). At the same time, success at the local level will be enhanced to the extent that sector leaders at the state and national level are working together to achieve state and federal support for such efforts.

In describing each sector, we mentioned groups within that sector that are working on reform. At the same time, 
there are numerous foundations and advocacy organizations that are working on the issues we address in this paper. Two behavioral science organizations that are specifically working to advance effective action are the Coalition of Behavioral Science Organizations (CBSO) which supported the writing of this paper and the National Prevention Science Coalition, which is a member of the CBSO and which has more than sixty national organizations affiliated with it. A formal coalition among all of these organizations is an important next step for advancing the goals we have proposed. The process of creating such a coalition would begin by inviting an initial group of organizations to formally create the coalition.

\section{Public Education}

The major impetus for changes in public policy and practice are the reports of the National Academy of Science, Engineering, and Medicine, Surgeon Generals' Reports, monographs of the National Institutes of Health, and reports of the Centers for Disease Control and Prevention. With the publication of the recent NASEM reports on poverty reduction and the promotion of mental, emotional, and behavioral health, the Coalition of Behavioral Science Organizations and the National Prevention Science Coalition are working to publicize and build on the recommendations of these reports.

Behavioral scientists are beginning to do more to educate the public about how we can evolve a society that enhances everyone's well-being. NPSC is regularly doing Congressional briefings and publishing oped pieces in major national outlets. However, it is no longer possible to rely solely on mainstream media. Since the advent of social media, it has become possible for numerous actors to reach a large audience with views, misinformation, and hateful rhetoric that would never have been widely disseminated previously (Marantz 2019). This fact has only recently come to the attention of people working mainstream media (Haidt and Rose-Stockwell 2019). It is imperative that those of us who are trying to influence movement in the direction of supporting everyone's well-being, make more and better use of social media to promote understanding of what is needed to improve human well-being.

\section{A Research Agenda}

We believe that the two most important priorities for research are the development of a national system for monitoring both family well-being and neighborhood and community disadvantage and the development and testing of comprehensive interventions to reduce disadvantage and enhance family well-being.

\section{Valid Indices of Family and Community Well-Being}

If the nation is going to be guided to steadily increase family well-being and reduce community disadvantage, then it needs valid and widely accepted indices of each type of well-being. Ultimately, these indices should be reported annually by the federal government in the same way the indices of community economic well-being are monitored and reported. With respect to child and family well-being, the Urban Institute recently reported Well-Being and Basic Needs Survey that is an example of the type of survey system that is needed. At the same time, systems are being created to track conditions in neighborhoods and communities. Acevedo-Garcia et al. (2020) have a system that reports on the conditions in communities that are likely to enhance or hinder family well-being. Ultimately every community should be able to track well-being in their neighborhoods.

The COVID-19 pandemic has exposed virtually the entire nation to the practice of tracking well-being down to the level of the community. Because of the danger of a high rate of COVID-19 infections, people watch with great interest whether case rates were increasing or decreasing. States track what was working in other states and adopt practices that seem to be working. These same procedures are relevant to achieving changes in other aspects of well-being. Granted the outcomes that would be focused on with a system that was monitoring family and community well-being will not attract as much attention as one that is tracking deaths due to a virus. However, that is in part because the public has not been educated about the fact that family and community well-being are critical for the prevention of premature death and virtually all of the psychological and behavioral problems that costs our nation so much.

Community-level monitoring of child and family wellbeing and the contextual conditions that affect families will provide the criteria by which a community can assess its progress and can maintain or modify its practices in light of the data. This process can shape the practices of each sector. For example, reductions in juvenile crime should result from adoption of evidence-based school, family, and juvenile justice practices. Although it will not be possible to precisely attribute reductions in juvenile crime to one of these systems, each system can monitor how many youth and families it is reaching with evidence-based practices and can assess the impact of their services.

\section{Research on Ameliorating Disadvantage in Communities of Concentrated Disadvantage}

Evidence of the value of both economic development efforts and programs targeting families and schools suggests it is time to test comprehensive interventions that simultaneously address all risk factors for problems for which we have some 
effective solutions. Interventions that only address family and school environments will leave many families in poverty. Interventions that target only economic well-being will not ameliorate patterns of conflict in families, nor school cultures that undermine development and well-being (Van Ryzin et al. 2018).

A variety of intervention strategies and evaluation methods have been used, but most have no connection to other work on this problem. There is research on workforce development, economic development, and family and school interventions that could contribute to reducing intergenerational poverty. There are community interventions focused on preventing adolescent problem behavior (Hawkins et al. 2014), efforts to strengthen supports for child and adolescent development, and collective impact approaches to bringing all sectors of communities together to address challenges. However, a truly comprehensive framework for addressing the tangle of problems will likely require all of these strategies.

The principles of community organizing (Hawkins et al. 2009; Minkler 2012) and collective impact (Cabaj and Weaver 2016) are foundational for a comprehensive intervention. Each of the sectors of the community needs to engage in a participatory process in which the community identifies the actions they want to take to improve wellbeing. As we indicated above, the efforts of each sector to enhance well-being will benefit from success of other sectors. To the extent that each sector supports other sectors efforts, synergistic benefits are likely.

A second line of research that is essential for any comprehensive intervention consists of efforts to enhance economic well-being in the neighborhood and communities. The Brookings Institution (Shambaugh and Nunn 2018) reviewed research on place-based strategies to improve economic well-being in communities or neighborhoods of concentrated disadvantage. These included job training, tax benefits for investment in neighborhoods, subsidized employment, involving research universities in economic development, and extending the reach of existing health and nutrition programs. Because of the limited number of experimental evaluations of these strategies, evidence for the benefit of programs such as enterprise and opportunity zones is, at best, weak.

A third component of such interventions would be the implementation of family and school interventions that have proven benefit in enhancing family and school supports for successful development. Table 1 indicates activities that promote prosociality at every stage of development, from preconception through young adulthood. To our knowledge, no community has systematically implemented a comprehensive lifespan intervention and carefully assessed its impact. The closest we have found is the Harlem Children's Zone, whose results are encouraging (Whitehurst and Croft 2010).

There are also likely to be synergistic effects of efforts at different phases of development. Perhaps a child did not develop cognitive problems because her parents did everything they could to ensure her well-being in utero. As a result, a kindergarten class may have one less disruptive and uncooperative child. One more child will be able to read at grade level by third grade. If that child encounters adversity later in childhood (e.g., if a parent dies), she will benefit from good programs such as the one Sandler and colleagues

Table 1 Activities promoting prosocial behavior at all developmental stages

\begin{tabular}{|c|c|c|c|}
\hline Developmental phase & Family supports & School supports & Healthcare \\
\hline Preconception & $\begin{array}{l}\text { Pregnancy prevention; health pro- } \\
\text { motion; substance use prevention }\end{array}$ & $\begin{array}{l}\text { Pregnancy prevention; health promo- } \\
\text { tion; substance use prevention }\end{array}$ & $\begin{array}{l}\text { Pregnancy prevention; health promotion; } \\
\text { substance use prevention }\end{array}$ \\
\hline Pregnancy & Home visiting & $\begin{array}{l}\text { High school curriculum on child } \\
\text { development }\end{array}$ & Prenatal care \\
\hline First two years of life & Evidence-based family interventions & $\begin{array}{l}\text { High school curriculum on child } \\
\text { development }\end{array}$ & Well-baby visits \\
\hline Early childhood & Evidence-based family interventions & High-quality preschools & $\begin{array}{l}\text { Screening, Brief Intervention, and Refer- } \\
\text { ral to Treatment (SBIRT); minimized } \\
\text { use of psycho-stimulants }\end{array}$ \\
\hline Childhood & Evidence-based family interventions & $\begin{array}{l}\text { PAX Good Behavior Game and/or } \\
\text { other evidence-based social-emo- } \\
\text { tional learning programs; effective } \\
\text { instruction }\end{array}$ & $\begin{array}{l}\text { SBIRT; minimized use of psycho- } \\
\text { stimulants }\end{array}$ \\
\hline Early adolescence & Evidence-based family interventions & $\begin{array}{l}\text { Cooperative learning; evidence-based } \\
\text { preventive interventions }\end{array}$ & $\begin{array}{l}\text { SBIRT; minimized use of psycho- } \\
\text { stimulants }\end{array}$ \\
\hline Adolescence & Evidence-based family interventions & $\begin{array}{l}\text { Cooperative learning; evidence-based } \\
\text { preventive interventions }\end{array}$ & $\begin{array}{l}\text { SBIRT; minimized use of psycho- } \\
\text { stimulants }\end{array}$ \\
\hline Young adulthood & $\begin{array}{l}\text { Evidence-based pre-marital and } \\
\text { marital counseling and classes }\end{array}$ & & SBIRT \\
\hline
\end{tabular}


(Sandler et al. 1992) developed to aid in coping with a death in the family.

Most evaluations of family and school programs with demonstrated benefits have been in contexts without other programs in place. And although the benefits of many interventions are significant, the size of their impact is generally small (Jones et al. 2019), and there is no evidence that their effectiveness has been increasing over time (Weisz et al. 2019). One reason may be that these interventions are implemented in isolation both from many of the contextual conditions that affect behavior and from ameliorative interventions at other stages of development. It is likely that ensuring supports for families and schools at every stage of development can produce a larger impact on population well-being than any of these interventions in isolation.

In addition to the many programs and policies with the potential to enhance well-being in communities, it may be beneficial to promote compassion and kindness. People who have faced numerous adverse experiences are likely to be hyper-vigilant and to read others as threatening; this is an adaptive orientation in such an environment (Ellis et al. 2012). A community-wide effort to promote patient, caring, and kind interactions may contribute to reducing aversive interactions that not only maintain suspicion and distrust but lead to high levels of stress-related physiological processes that contribute to premature death (Miller et al. 2011).

For example, imagine a family moving into a community that has increasingly organized around nurturing values, and that has explicit goals and procedures for promoting prosocial behavior. Imagine this family has a long history of stressful contact with schools, the criminal justice system, healthcare providers, and perhaps neighbors. Such a history is common in communities of concentrated disadvantage.

The family's first experience in the community is likely to be enrolling their children in school, which may make them feel nervous and defensive. But suppose the school has a program to invite new families to discover how it supports children's prosocial behavior. Suppose that staff convey that they like and admire the children. The family relaxes a bit, which is likely to promote positive interactions at home.

Now imagine that in every encounter in the community over the next few weeks, they meet people who show an interest in them and are welcoming and helpful. Each positive encounter can contribute to family members becoming more comfortable while also conveying prosocial norms and reinforcing behavior.

\section{Developing the Most Effective Research Strategies}

The complexities involved in evaluating comprehensive community interventions have hampered progress in helping neighborhoods of concentrated disadvantage. Here we discuss what could strengthen this work.
Randomized trials are expensive and difficult to conduct in whole communities, especially if the intervention to be tested is multi-faceted. And, given the complexity of the multiple problems that need to be addressed, interventions need to be multi-faceted.

Randomized trials are useful for evaluating impact across cases, and they have demonstrated the value of numerous family and school interventions. However, they are not the best way to tease out functional relationships between environments and behavior. The family and school interventions that have been validated by randomized trials grew out of single-case experimental designs that revealed functional relationships between parents' and children's behavior (Kazdin 1978). Similarly, before we can test complex, multi-faceted interventions through randomized trials in multiple communities, we need to show they are working reliably in individual communities. Moreover, randomized trials require the assumption that all communities are alike in their needs and with regard to what will work. This makes it difficult to tailor an intervention to the needs of the community and still maintain consistency of the intervention across communities.

Greater use of interrupted time series designs would enhance research on communities (Biglan et al. 2000a, b). These designs involve obtaining repeated measures of an individual behavior or group action and assessing the impact of a well-defined intervention or independent variable on that time series.

Such multiple baseline designs could help to evaluate the impact of comprehensive interventions on the wide range of aspects of child and family well-being, including economic well-being, quality of family interactions, and psychological and behavioral functioning of children and parents. By monitoring well-being in three communities or neighborhoods and implementing a comprehensive intervention in one of the communities, while continuing monitoring, but not intervening in the other two communities, we can assess whether the intervention affects measures of well-being. If an effect is detected in the first community over, for example, two years, it can be implemented in a second community. If its effects are replicated in the second community, it can be implemented in a third. Such a design provides a valid experimental test of the impact of the intervention (Biglan et al. 2000a, b).

These methods are also useful for discovering the impact of individual interventions. For example, a community might implement the PAX Good Behavior Game (Jiang et al. 2016) in a series of three elementary schools and track its impact on disruptive behavior and students' behavioral functioning. The community might initially evaluate introduction of an evidence-based family intervention in a multiple baseline across four families. It could similarly stage and evaluate a $\$ 3,000$ per child allowance in terms of its impact on family 
relations. These assessments of individual programs would immediately show evidence of their efficacy, which could promote wider adoption. If they did not show benefits, the community could abandon the interventions or modify them until they worked.

The beauty of these designs is that providing immediate experimental assessment of the impact of an intervention can enable its improvement. Rather than requiring that each community get the same thing, these designs enable continuous quality improvement, so that successive communities receive an intervention modified by the improvements made in earlier implementations.

Although we believe that interrupted time series designs are the most efficient and effective strategy for developing effective interventions in neighborhoods of concentrated disadvantage, we also believe that it is impossible to say precisely what experimental strategies will be most productive. It would be a mistake to dictate that all interventions or all experimental procedures should have the same features.

One experimental method that should also be tried is the MOST design (Guastaferro and Collins 2019). These factorial designs are valuable for efficiently identifying which components of an intervention and which combination of components are most effective. For example, an important question in neighborhood interventions is the relative and combined impact of economic development interventions and interventions focused on changing behavior in families and schools. A factorial design would efficiently address this question. It would involve randomly assigning neighborhoods to one of four conditions: (a) a combination of economic development and school and family interventions; (b) economic development interventions alone; (c) school and family strategies alone; or (d) no intervention. This design would allow assessment of the impact of each component, as well as the impact of the comprehensive intervention.

\section{Conclusion}

We hope that this paper has made the case for a new initiative to address the problem of concentrated disadvantage in America. The extent of the problem is clear. Its impact on the health and well-being of people living in these places is well-established. Its harm to the rest of the nation is measured in the costs of poor health, drug use disorders, overdose deaths, and lost productivity. The policies and programs that can ameliorate these conditions are clear.

This conclusion is being written on the day in which the U.S. became the country with the greatest number of COVID-19 cases. The nation and the world are getting a lesson in how to think about public health. The entire world has been mobilized to do everything it can to prevent people from becoming infected. In the process millions of people have learned to think about the entire population. The incidence and prevalence of problems in entire populations has become as important as the individual case.

This gives us an opportunity to bring attention to many other problems in society that would be best dealt with through public health strategies. Every significant psychological, behavioral, and health problem can be thought of in terms of its incidence and prevalence. Moreover, these problems are intertwined. This means that where we have high levels of one problem we are likely to high levels of others. And, specifically, these problems are concentrated in neighborhoods and communities that are high in poverty, substance use disorders, and social conflict. Thus, efforts to greatly reduce the number of families that are affected by disadvantage will have limited success if we do not focus on reducing the prevalence of highly disadvantaged places.

Making a difference in these places will require policies and programs that reduce harmful contextual conditions such as poverty, homelessness, and discrimination, as well as programs that directly assist families and schools in adopting the most nurturing practices. The evidence that we can affect these problems is substantial. However, the challenge is to develop and evaluate comprehensive efforts to address multiple risk factors at every stage of development. Putting in place such efforts will require a coalition of all sectors of society. If we can learn to speak with one voice about the harm that is being done by allowing children to be raised in concentrated disadvantage and the fact that we have policies and programs that could greatly reduce disadvantage, we may be able to achieve unprecedented improvements in the well-being of children and families in the USA.

\section{Compliance with Ethical Standards}

Conflict of interest The authors declare that they have no conflict of interest.

Ethical Approval This article does not contain any data from any studies with human participants that were performed by any of the authors.

\section{References}

Acevedo-Garcia, D., Noelke, C., McArdle, N., Sofer, N., Huntington, N., Hardy, E., et al. (2020). The Geography of Child Opportunity: Why Neighborhoods Matter for Equity. Brandeis: The Heller School for Social Policy and Management. Retrieved from diversitydatakids.org.

Alexander, M. (2012). The New Jim Crow. New York: The New Press. American Psychological Association Zero Tolerance Task Force. (2008). Are zero tolerance policies effective in the schools?: An evidentiary review and recommendations. American Psychologist, 63(9), 852-862. https://doi. org/10.1037/0003-066X.63.9.852. 
American Psychological Association. (2016). Discrimination Linked to Increased Stress, Poorer Health, American Psychological Association Survey Finds. Retrieved from https://www.apa.org/news/ press/releases/2016/03/impact-of-discrimination

American Psychological Association. (n.d.). Education and Socioeconomic Status. Retrieved from https://www.apa.org/pi/ses/resou rces/publications/education

Anda, R. F., Croft, J. B., Felitti, V. J., Nordenberg, D., Giles, W. H., Williamson, D. F., et al. (1999). Adverse childhood experiences and smoking during adolescence and adulthood. Journal of the American Medical Association, 282(17), 1652-1658.

Anda, R. F., Whitfield, C. L., Felitti, V. J., Chapman, D., Edwards, V. J., Dube, S. R., et al. (2002). Adverse childhood experiences, alcoholic parents, and later risk of alcoholism and depression. Psychiatric Services (Washington, D. C.), 53(8), 1001-1009. https://doi.org/10.1176/appi.ps.53.8.1001.

Anda, R., Dong, M., Brown, D., Felitti, V., Giles, W., Perry, G., et al. (2009). The relationship of adverse childhood experiences to a history of premature death of family members. BMC Public Health, 9(1), 106.

Armstrong, M. J., Mottershead, T. A., Ronksley, P. E., Sigal, R. J., Campbell, T. S., \& Hemmelgarn, B. R. (2011). Motivational interviewing to improve weight loss in overweight and/or obese patients: A systematic review and meta-analysis of randomized controlled trials. Obesity Reviews, 12(9), 709-723. https://doi. org/10.1111/j.1467-789X.2011.00892.x.

Ayotte, B. J., Margrett, J. A., \& Hicks-Patrick, J. (2010). Physical activity in middle-aged and young-old adults: the roles of self-efficacy, barriers, outcome expectancies, self-regulatory behaviors and social support. J Health Psychol, 15(2), 173-185. https://doi. org/10.1177/1359105309342283.

B Corporation (n.d.). "About B Corps." Retrieved March 30, 2020, from https://bcorporation.net/about-b-corps.

Bandura, A. (2004). Health promotion by social cognitive means. Health Education and Behavioral, 31(2), 143-164. https://doi. org/10.1177/1090198104263660.

Berge, J. M., Wall, M., Larson, N., Loth, K. A., \& Neumark-Sztainer, D. (2013). Family functioning: associations with weight status, eating behaviors, and physical activity in adolescents. Journal of Adolescent Health, 52(3), 351-357. https://doi.org/10.1016/j. jadohealth.2012.07.006.

Bergen, A. W., Mallick, A., Nishita, D., Wei, X., Michel, M., Wacholder, A., et al. (2012). Chronic psychosocial stressors and salivary biomarkers in emerging adults. Psychoneuroendocrinology, 37(8), 1158-1170. https://doi.org/10.1016/j.psyne uen.2011.11.010

Bernard-Bonnin, A.-C., \& Society, C. P., Health, M., \& Committee, D. D. (2004). Maternal depression and child development. Paediatrics Child Health, 9(8), 575-583. https://doi.org/10.1093/ pch/9.8.575.

Berta, M., \& Zarling, A. (2019). A preliminary examination of an acceptance and commitment therapy-based program for incarcerated domestic violence offenders. Violence and Victims, 34(2), 213-228. https://doi.org/10.1891/0886-6708.Vv-d-17-00106.

Biglan, A. (2004a). Contextualism and the development of effective prevention practices. Prevention Science, 5(1), 15-21.

Biglan, A. (2004b). Direct written testimony in the case of the U.S.A. vs. Phillip Morris et al. U.S. Department of Justice.

Biglan, A. (2015). The nurture effect: How the science of human behavior can improve our lives and our world. Oakland, CA: New Harbinger.

Biglan, A. (2019). Healthcare for all is essential: And it's not enough. Retrieved from https://medium.com/@tony_71103/healthcare -for-all-is-essential-and-its-not-enough-86ad4feda3d8

Biglan, A. (2020a). Rebooting capitalism: How behavioral science can forge a society that works for everyone. Values to Action.
Biglan, A. (2020b). "How and why the food industry makes americans sick." Social Pathologies Series. Retrieved March 12, 2020, from https://evolution-institute.org/how-and-why-the-food-industrymakes-americans-sick

Biglan, A. (2020c). "How cigarette marketing killed 20 million people." Social Pathologies Series. Retrieved March 12, 2020, from https://evolution-institute.org/how-cigarette-marketing-killed-20million-people/.

Biglan, A. (2020d). "Big pharma and the death of Americans." Social Pathologies Series. Retrieved March 12, 2020, from https://evolu tion-institute.org/big-pharma-and-the-death-of-americans.

Biglan, A. (2020e). "How free market ideology resulted in the great recession." Social Pathologies Series. Retrieved March 12, 2020, from https://evolution-institute.org/how-free-market-ideologyresulted-in-the-great-recession.

Biglan, A. (2020f). The fossil fuel industry: The greatest threat to human wellbeing. Social Pathologies Series. Retrieved March 12, 2020, from https://evolution-institute.org/the-fossil-fuelindustry-the-greatest-threat-to-human-wellbeing.

Biglan, A. (2020g). "The crisis of capitalism." Social Pathologies Series. Retrieved March 12, 2020, from https://evolution-insti tute.org/the-crisis-of-capitalism/.

Biglan, A., \& Embry, D. D. (2013). A framework for intentional cultural change. Journal of Contextual Behavioral Science, 2(3), 95-104.

Biglan, A., Ary, D. V., \& Wagenaar, A. C. (2000). The value of interrupted time-series experiments for community intervention research. Prevention Research, 1(1), 31-49.

Biglan, A., Ary, D. V., Smolkowski, K., Duncan, T., \& Black, C. (2000). A randomised controlled trial of a community intervention to prevent adolescent tobacco use. Tobacco Control, 9(1), 24-32.

Biglan, A., Brennan, P. A., Foster, S. L., \& Holder, H. D. (2004). Helping adolescents at risk: Prevention of multiple problem behaviors. New York: Guilford.

Biglan, A., Flay, B. R., Embry, D. D., \& Sandler, I. N. (2012). The critical role of nurturing environments for promoting human well-being. American Psychologist, 67(4), 257-271. https://doi. org/10.1037/a0026796.

Biglan, A., Johansson, M., Van Ryzin, M., \& Embry, D. (in press). Scaling up and scaling out: Consilience and the evolution of more nurturing societies. Clinical Psychology Review.

Biglan, A., Van Ryzin, M., Moore, K., Mauricci, M., \& Mannon, I. (2019). The socialization of boys and men inthe modern era: An evolutionary mismatch. Development and Psychopathology, 31, 1789-1799. https://doi.org/10.1017/S0954579419001366.

Bradshaw, C. P., Waasdorp, T. E., \& Leaf, P. J. (2012). Effects of school-wide positive behavioral interventions and supports on child behavior problems. Pediatrics, 130(5), e1136-e1145. https ://doi.org/10.1542/peds.2012-0243.

Brody, G. H., Yu, T., Miller, G. E., \& Chen, E. (2016). Resilience in adolescence, health, and psychosocial outcomes. Pediatrics; https://doi.org/10.1542/peds.2016-1042.

Business Roundtable (n.d.). Business Roundtable Redefines the Purpose of a Corporation to Promote 'An Economy That Serves All Americans'. Retrieved March 30, 2020, from https://www.busin essroundtable.org/business-roundtable-redefines-the-purpose-ofa-corporation-to-promote-an-economy-that-serves-all-americans.

Cabaj, M., \& Weaver, L. (2016). Collective impact 3.0: An evolving framework for community change. Waterloo, ON

Calhoun, S., Conner, E., Miller, M., \& Messina, N. (2015). Improving the outcomes of children affected by parental substance abuse: A review of randomized controlled trials. Substance Abuse and Rehabilitation, 6, 15-24. https://doi.org/10.2147/SAR.S46439.

Catalano, R. F., Berglund, M. L., Ryan, J. A., Lonczak, H. S., \& Hawkins, J. D. (2002). Positive youth development in the United 
States: Research findings on evaluations of positive youth development programs. Prevention \& Treatment, 5(1), 15a.

Centers for Disease Control and Prevention. (1996). The great American smokeout-November 21, 1996. Morbidity and Mortality Weekly Report, 45(44), 961-984.

Chen, M., \& Chan, K. L. (2016). Effects of parenting programs on child maltreatment prevention: A meta-analysis. Trauma Violence Abuse, 17(1), 88-104. https://doi.org/10.1177/1524838014 566718.

Chetty, R., Stepner, M., Abraham, S., Lin, S., Scuderi, B., Turner, N., et al. (2016). The Association Between Income and Life Expectancy in the United States, 2001-2014. Journal of the American Medical Association, 315(16), 1750-1766. https:// doi.org/10.1001/jama.2016.4226.

Child Trends Databank. (2019). Children in poverty. Retrieved from https://www.childtrends.org/?indicators=children-in-poverty

Dallaire, D., Zeman, J., \& Thrash, T. (2015). Differential effects of type of children's contact with their jailed mothers and children's behavior problems. In J. Poehlmann-Tynan (Ed.), Children's contact with incarcerated parents (pp. 23-38). Cham: Springer.

DeBaryshe, B. D., Patterson, G. R., \& Capaldi, D. M. (1993). A performance model for academic achievement in early adolescent boys. Developmental Psychology, 29(5), 795-804.

Dishion, T. J., \& Snyder, J. (2014). Oxford handbook of coercive relationship dynamics: Basic mechanisms, developmental processes, and intervention applications (T. J. Dishion \& J. Snyder Eds.). New York: Oxford University Press.

Dishion, T. J., \& Snyder, J. (2016). Oxford handbook of coercive relationship dynamics (T. J. Dishion \& J. Snyder Eds.). New York, NY: Oxford University Press.

Dishion, T. J., Dodge, K. A., \& Lansford, J. E. (2006). Findings and recommendations: A blueprint to minimize deviant peer influence in youth interventions and programs. In K. A. Dodge, T. J. Dishion, \& J. E. Lansford (Eds.), Deviant peer influences in programs for youth: Problems and solutions (pp. 366-394). New York, NY: Guilford.

Duncombe, C. (2017). Unequal opportunities: Fewer resources, worse outcomes for students in schools with concentrated poverty. Retrieved from https://www.thecommonwealthinstitute. org/2017/10/26/unequal-opportunities-fewer-resources-worse -outcomes-for-students-in-schools-with-concentrated-poverty/

Eddy, J. M., \& Poehlmann, J. (2019). Handbook on children with incarcerated parents: Research, policy, and practice. New York: Springer International Publishing.

Ellis, B. J., \& Bjorklund, D. F. (2012). Beyond mental health: An evolutionary analysis of development under risky and supportive environmental conditions: An introduction to the special section. Developmental Psychology, 48(3), 591-597.

Ellis, B. J., Del Giudice, M., Dishion, T. J., Figueredo, A. J., Gray, P., Griskevicius, V., et al. (2012). The evolutionary basis of risky adolescent behavior: Implications for science, policy, and practice. Developmental Psychology, 48(3), 598-623. https://doi. org/10.1037/a0026220.

Embry, D. D. (2002). The Good Behavior Game: A best practice candidate as a universal behavioral vaccine. Clinical Child and Family Psychology Review, 5(4), 273-297.

Enns, P. K., Yi, Y., Comfort, M., Goldman, A. W., Lee, H., Muller, C., et al. (2019). What percentage of Americans have ever had a family member incarcerated?: Evidence from the family history of incarceration survey (FamHIS). Socius, 5.

Families USA. (2018). Federal Poverty Guidelines. Retrieved from https://familiesusa.org/product/federal-poverty-guidelines

Fazel, S., \& Wolf, A. (2015). A systematic review of criminal recidivism rates worldwide: Current difficulties and recommendations for best practice. PLOS ONE, 10(6), e0130390-e0130390. https ://doi.org/10.1371/journal.pone.0130390.
Feldstein, A. C., \& Glasgow, R. E. (2008). A practical, robust implementation and sustainability model (PRISM). Joint Commission Journal On Quality And Patient Safety/Joint Commission Resources, 34(4), 228-243.

Felitti, V. J., Anda, R. F., Nordenberg, D., Williamson, D. F., Spitz, A. M., Edwards, V., et al. (1998). Relationship of childhood abuse and household dysfunction to many of the leading causes of death in adults. The Adverse Childhood Experiences (ACE) Study. American Journal of Prevention Medicine, 14(4), 245-258.

Fontenot, K., Semega, J., \& Kollar, M. (2018). Income and Poverty in the United States: 2017 (P60-263). Retrieved from United States Census Bureau: https://www.census.gov/library/publicatio ns/2018/demo/p60-263.html

Ford, J. A., Sacra, S. A., \& Yohros, A. (2017). Neighborhood characteristics and prescription drug misuse among adolescents: The importance of social disorganization and social capital. International Journal of Drug Policy, 46, 47-53. https://doi. org/10.1016/j.drugpo.2017.05.001.

Galobardes, B., Lynch, J. W., \& Smith, G. D. (2004). Childhood socioeconomic circumstances and cause-specific mortality in adulthood: systematic review and interpretation. Epidemiologic Reviews, 26, 7-21. https://doi.org/10.1093/epirev/mxh008.

Galobardes, B., Lynch, J. W., \& Smith, G. D. (2008). Is the association between childhood socioeconomic circumstances and cause-specific mortality established? Update of a systematic review. Journal of Epidemiology and Community Health, 62(5), 387-390.

Garbacz, S. A. (Ed.). (2020). Establishing family-school partnerships in school psychology: Critical skills. New York: Routledge.

Garbacz, S. A., Herman, K. C., Thompson, A. M., \& Reinke, W. M. (2017). Family engagement in education and intervention: Implementation and evaluation to maximize family, school, and student outcomes. Journal of School Psychology, 62, 1-10.

García, E., \& Weiss, E. (2017). Education inequalities at the school starting gate: Gaps, trends, and strategies to address them. Retrieved from Washington, DC: epi.org/132500

Gollwitzer, P. M. (1999). Implementation intentions: Strong effects of simple plans. American Psychologist, 54(7), 493-503. https:// doi.org/10.1037/0003-066X.54.7.493.

Guastaferro, K., \& Collins, L. M. (2019). Achieving the Goals of Translational Science in Public Health Intervention Research: The Multiphase Optimization Strategy (MOST). American Journal of Public Health. https://doi.org/10.2105/AJPH.2018.30487 4.

Haidt, J., \& Rose-Stockwell, T. (2019). The dark psychology of social networks. The Atlantic Monthly. Retrieved March 30, 2020, from https://www.theatlantic.com/magazine/archive/2019/12/socia 1-media-democracy/600763/.

Haines, J., Rifas-Shiman, S. L., Horton, N. J., Kleinman, K., Bauer, K. W., Davison, K. K., et al. (2016). Family functioning and quality of parent-adolescent relationship: Cross-sectional associations with adolescent weight-related behaviors and weight status. The International Journal of Behavioral Nutrition and Physical Activity, 13(1), 68.

Halliday, J., Palma, C., Mellor, D., Green, J., \& Renzaho, A. (2013). The relationship between family functioning and child and adolescent overweight and obesity: A systematic review (Vol. 38).

Hart-Shegos, E. (1999). Homelessness and its effects on children. A Report Prepared for the Family Housing Fund.

Hawkins, J. D., Oesterle, S., Brown, E. C., Arthur, M. W., Abbott, R. D., Fagan, A. A., et al. (2009). Results of a type 2 translational research trial to prevent adolescent drug use and delinquency: A test of Communities That Care. Archives of Pediatrics \& Adolescent Medicine, 163(9), 789-798.

Hawkins, J., Oesterle, S., Brown, E. C., Abbott, R. D., \& Catalano, R. F. (2014). Youth problem behaviors 8 years after implementing 
the communities that care prevention system: A communityrandomized trial. JAMA Pediatrics, 168(2), 122-129.

Hayes, S. C. (2019). A liberated mind: How to pivot toward what matters. New York: Penguin Publishing Group.

Homer, C. J. (2009). Responding to the childhood obesity epidemic: From the provider visit to health care policy-Steps the health care sector can take. Pediatrics, 123(Supplement 5), S253S257. https://doi.org/10.1542/peds.2008-2780B.

Insley, A. C. (2001). Suspending and expelling children from educational opportunity: Time to reevaluate zero tolerance policies. Am. UL Rev., 50, 1039.

Institute of Medicine, \& National Research Council. (2014). New directions in child abuse and neglect research. Washington, DC: The National Academies Press.

Institute of Medicine. (2009). Preventing mental, emotional, and behavioral disorders among young people: progress and possibilities. Washington, DC: The National Academies Press.

Jarjoura, R., Triplett, R., \& Brinker, G. P. (2002). Growing up poor: Examining the link between persistent childhood poverty and delinquency. Journal of Quantitative Criminology, 18(2), 159187. https://doi.org/10.1023/A:1015206715838

Jeynes, W. (2012). A meta-analysis of the efficacy of different types of parental involvement programs for urban students. Urban Education, 47(4), 706-742. https://doi.org/10.1177/00420 85912445643.

Jiang, D., Santos, R., Mayer, T., \& Boyd, L. (2016). Latent Transition Analysis for Program Evaluation with Multivariate Longitudinal Outcomes.

Johansson, M., Biglan, A., \& Embry, D. (under revision). The PAX Good Behavior Game: One Model for Evolving a More Nurturing Society. Clinical Child and Family Psychology Review.

Jones, P. J., Mair, P., Kuppens, S., \& Weisz, J. R. (2019). An upper limit to youth psychotherapy benefit? A meta-analytic Copula approach to psychotherapy outcomes. Clinical Psychological Science, 7(6), 1434-1449.

Kahan, S., Wilson, D. K., \& Sweeney, A. M. (2018). The role of behavioral medicine in the treatment of obesity in primary care. Medical Clinics of North America, 102(1), 125-133. https ://doi.org/10.1016/j.mena.2017.09.002.

Kania, J., \& Karmer, M. (2011). Collective Impact. Retrieved from https://ssir.org/articles/entry/collective_impact

Kaplan, R. M. (2019). More than Medicine: the Broken Promise of American Health. Cambridge, MA: Harvard University Press.

Karriker-Jaffe, K. J. (2013). Neighborhood socioeconomic status and substance use by U.S. adults. Drug and Alcohol Dependence, 133(1), 212-221.

Kasser, T. (2011). Cultural values and the well-being of future generations: A cross-national study. Journal of Cross-Cultural Psychology, 42(2), 206-215.

Kasser, T. (2016). Materialistic values and goals. Annual Review of Psychology, 67, 489-514. https://doi.org/10.1146/annurevpsych-122414-033344.

Kaufman, J., Salas, L., Komro, K. A., \& Livingston, M. D. (2020). Effect of an increased minimum wage by unemployment rate on suicide in the United States. Journal of Epidemiology \& Community Health. https://doi.org/10.1136/jech-2019-212981.

Kazdin, A. E. (1978). History of behavior modification: Experimental foundations of contemporary research. Baltimore, MD: University Park Press.

Kellam, S. G., Wang, W., Mackenzie, A. C., Brown, C. H., Ompad, D. C., Or, F., et al. (2014). The impact of the Good Behavior Game, a universal classroom-based preventive intervention in first and second grades, on high-risk sexual behaviors and drug abuse and dependence disorders into young adulthood. Prevention Science, 15(Suppl 1), S6-18. https://doi.org/10.1007/ s11121-012-0296-z.
Kerman, P. (n.d.). Justice Reform Organizations. Retrieved March 30, 2020, from https://piperkerman.com/justice-reform/justice-refor m-organizations/.

Kitzman-Ulrich, H., Wilson, D. K., St George, S. M., Lawman, H., Segal, M., \& Fairchild, A. (2010). The integration of a family systems approach for understanding youth obesity, physical activity, and dietary programs. Clinical Child and Family Psychology Review, 13(3), 231-253. https://doi.org/10.1007/s1056 7-010-0073-0.

Komro, K. A., Livingston, M. D., Markowitz, S., \& Wagenaar, A. C. (2016). The effect of an increased minimum wage on infant mortality and birth weight. American Journal of Public Health, 106(8), 1514-1516. https://doi.org/10.2105/AJPH.2016.303268.

Komro, K. A., Tobler, A. L., Delisle, A. L., O’Mara, R. J., \& Wagenaar, A. C. (2013). Beyond the clinic: Improving child health through evidence-based community development. BMC Pediatrics, 13(1), 172. https://doi.org/10.1186/1471-2431-13-172.

Kristof, N. D., \& WuDunn, S. (2020). Tightrope: Americans reaching for hope. New York: Afred A. Knopf.

Leslie, L. K., Mehus, C. J., Hawkins, J. D., Boat, T., McCabe, M. A., Barkin, S., et al. (2016). Primary health care: Potential home for family-focused preventive interventions. American Journal of Preventive Medicine, 51(4), S106-S118. https://doi. org/10.1016/j.amepre.2016.05.014.

Lewis, K. M., DuBois, D. L., Bavarian, N., Acock, A., Silverthorn, N., Day, J., et al. (2013). Effects of Positive Action on the emotional health of urban youth: a cluster-randomized trial. Journal of Adolescent Health, 53(6), 706-711. https://doi.org/10.1016/j. jadohealth.2013.06.012.

Lewis, K. M., Schure, M. B., Bavarian, N., DuBois, D. L., Day, J., Ji, P., et al. (2013). Problem behavior and urban, low-income youth: a randomized controlled trial of positive action in Chicago. American Journal of Preventive Medicine, 44(6), 622-630. https://doi. org/10.1016/j.amepre.2013.01.030.

Lipari, R. N., \& Van Horn, S. L. (2017). Children living with parents who have a substance use disorder. The CBHSQ Report: August 24, 2017. Rockville, MD: Retrieved from https://www.samhs a.gov/data/sites/default/files/report_3223/ShortReport-3223.pdf

Lipsey, M. W. (1992). Juvenile delinquency treatment: A meta-analytic inquiry into the variability of effects. In T. D. Cook, H. M. Cooper, D. S. Cordray, H. Hartmann, L. V. Hedges, R. J. Light, T. A. Louis, \& F. Mosteller (Eds.), Meta-analysis for explanation (pp. 83-127). New York: Russell Sage.

Lipsey, M. W., Howell, J. C., Kelly, M. R., Chapman, G., \& Carver, D. (2010). Improving the effectiveness of juvenile justice programs. Washington, DC: Center for Juvenile Justice Reform at Georgetown University.

Ludwig, J., Sanbonmatsu, L., Gennetian, L., Adam, E., Duncan, G. J., Katz, L. F., et al. (2011). Neighborhoods, obesity, and diabetes-A randomized social experiment. New England Journal of Medicine, 365(16), 1509-1519. https://doi.org/10.1056/NEJMs a1103216.

Mackey, J., \& Sisodia, R. (2014). Conscious capitalism, with a new preface by the authors: Liberating the heroic spirit of business. Boston, MA: Harvard Business School Publishing Corporation.

Marantz, A. (2019). Antisocial: Online extremists, techno-utopians, and the hijacking of the American conversation. United States of America: Viking.

Markowitz, S., Komro, K. A., Livingston, M. D., Lenhart, O., \& Wagenaar, A. C. (2017). Effects of state-level earned income taxcredit laws in the U.S. on maternal health behaviors and infant health outcomes. National Institute on Minority Health and Health Disparities, NIH. National Bureau of Economic Research. Retrieved from https://www.nber.org/papers/w23714

Martinez, S. (2009). A system gone berserk: How are zero-tolerance policies really affecting schools? Preventing School Failure: 
Alternative Education for Children and Youth, 53(3), 153-158. https://doi.org/10.3200/PSFL.53.3.153-158.

Mâsse, L. C., Watts, A. W., Barr, S. I., Tu, A. W., Panagiotopoulos, C., Geller, J., et al. (2014). Individual and household predictors of adolescents' adherence to a web-based intervention. Annals of Behavioral Medicine, 49(3), 371-383. https://doi.org/10.1007/ s12160-014-9658-z.

Matthews, K. A., \& Gallo, L. C. (2011). Psychological perspectives on pathways linking socioeconomic status and physical health. Annual Review of Psychology, 62, 501-530. https://doi. org/10.1146/annurev.psych.031809.130711.

Michie, S., Abraham, C., Whittington, C., McAteer, J., \& Gupta, S. (2009). Effective techniques in healthy eating and physical activity interventions: a meta-regression. Health Psychology, 28(6), 690-701. https://doi.org/10.1037/a0016136.

Miller, G. E., Chen, E., \& Parker, K. J. (2011). Psychological stress in childhood and susceptibility to the chronic diseases of aging: Moving toward a model of behavioral and biological mechanisms. Psychological Bulletin, 137(6), 959-997. https://doi. org/10.1037/a0024768.

Miller, W. R., \& Rose, G. S. (2009). Toward a theory of motivational interviewing. The American Psychologist, 64(6), 527-537. https ://doi.org/10.1037/a0016830.

Minkler, M. (Ed.). (2012). Community Organizing and Community Building for Health and Welfare, 3rd addition. New Brunswick, NJ: Rutgers University Press.

Mitchell, S. D. (2014). Zero Tolerance Policies: Criminalizing Childhood and Disenfranchising the Next Generation of Citizens. Retrieved from https://openscholarship.wustl.edu/law_lawre view/vol92/iss $2 / 6$

National Academies of Sciences, Engineering, \& Medicine. (2019a). A Roadmap to Reducing Child Poverty. Washington, DC: The National Academies Press. Retrieved from https://doi. org/10.17226/25246

National Academies of Sciences, Engineering, \& Medicine. (2019b). Fostering healthy mental, emotional, and behavioral development in children and youth: A national agenda. Retrieved from https:// doi.org/10.17226/25201

National Alliance to End Homelessness. (2020). How many children and families experience homelessness? Retrieved from https:// endhomelessness.org/homelessness-in-america/who-experience s-homelessness/children-and-families/

National Public Radio, Robert Wood Johnson Foundation, \& Harvard T.H. Chan School of Public Health. (2018). Discrimination in America: Final Summary. Retrieved from https://cdn1.sph.harva rd.edu/wp-content/uploads/sites/94/2018/01/NPR-RWJF-HSPHDiscrimination-Final-Summary.pdf

National Research Council, \& Institute of Medicine. (2009). Preventing mental, emotional, and behavioral disorders among young people: Progress and possibilities. Committee on Prevention of Mental Disorders and Substance Abuse Among Children, Youth, and Young Adults: Research Advances and Promising Interventions. Board on Children, Youth, and Families, Division of Behavioral and Social Sciences and Education. Washington, DC: The National Academies Press.

Nestle, M. (2002). Food politics: How the food industry influences nutrition and health (California studies in food and culture). Berkeley, CA: University of California Press.

Nichols, A., \& Rothstein, J. (2016). The Earned Income Tax Credit. In R. A. Moffitt (Ed.), Economics of means-tested transfer programs in the United States (Vol. 2, pp. 137-218). Chicago, IL: University of Chicago Press.

OECD Family Database. (2018). CO2.2: Child poverty. Family Database. Retrieved from https://www.oecd.org/els/soc/CO_2_2_ Child_Poverty.pdf
Paluck, E. L., \& Green, D. P. (2009). Prejudice reduction: What works? A review and assessment of research and practice. Annual Review of Psychology, 60, 339-367.

Pampel, F. C., Krueger, P. M., \& Denney, J. T. (2010). Socioeconomic disparities in health behaviors. Annual Review of Sociology, 36, 349-370. https://doi.org/10.1146/annurev.soc.012809.102529.

Parke, R. D., \& Clarke-Stewart, K. A. (2001). From prison to home: The effect of incarceration and reentry on children, families, and communities. Retrieved from https://aspe.hhs.gov/basic-report/ effects-parental-incarceration-young-children\#Short

Pascoe, E. A., \& Smart Richman, L. (2009). Perceived discrimination and health: a meta-analytic review. Psychological Bulletin, 135(4), 531.

Patterson, G. R., Capaldi, D. M., \& Bank, L. (1992). Two paths to delinquency: The early- and late-starters models. In K. B. Rubin \& D. J. Pepler (Eds.), The development and treatment of childhood aggression. Hillsdale, NJ: L. Erlbaum Associates. (Reprinted from: In File).

Patterson, G. R., DeBaryshe, B. D., \& Ramsey, E. (1989). A developmental perspective on antisocial behavior. American Psychologist, 44(2), 329-335.

Pechmann, C., Biglan, A., Grube, J. W., \& Cody, C. (2012). Transformative consumer research for addressing tobacco and alcohol consumption. In D. Mick, S. Pettigrew, C. Pechmann, \& J. Ozanne (Eds.), Transformative consumer research for personal and collective well-being (pp. 353-390). New York: Springer.

Perrin, E. M., Finkle, J. P., \& Benjamin, J. T. (2007). Obesity prevention and the primary care pediatrician's office. Current opinion in pediatrics, 19(3), 354-361. https://doi.org/10.1097/MOP.0b013 e328151c3e9.

Peterson, B., Cramer, L., Fontaine, J., \& Institute, Urban. (2019). Policies and practices for children of incarcerated parents: Summarizing what we know and do not know. In J. M. Eddy \& J. Poehlmann (Eds.), Handbook on children with incarcerated parents: Research, policy, and practice. New York: Springer.

Pettigrew, T. F., \& Tropp, L. R. (2008). How does intergroup contact reduce prejudice? Meta-analytic tests of three mediators. European Journal of Social Psychology, 38(6), 922-934.

Pickett, K. E., \& Pearl, M. (2001). Multilevel analyses of neighbourhood socioeconomic context and health outcomes: A critical review. Journal Epidemiol Community Health, 55(2), 111-122.

Pickett, K. E., \& Wilkinson, R. G. (2010). Inequality: An underacknowledged source of mental illness and distress. The British Journal of Psychiatry, 197(6), 426-428.

Pickett, K. E., \& Wilkinson, R. G. (2015). Income inequality and health: a causal review. Social Science and Medicine, 128, 316326. https://doi.org/10.1016/j.socscimed.2014.12.031.

Prinz, R. J. (2019). A population approach to parenting support and prevention: The Triple P System. The Future of Children, 29(1), $123-143$.

Prinz, R. J. (2012). Effective parenting to prevent adverse outcomes and promote child well-being at a population level. In D. Mick, S. Pettigrew, C. Pechmann, \& J. Ozanne (Eds.), Transformative consumer research for personal and collective well-being (pp. 585-598). New York: Taylor \& Francis.

Putnam, R. D. (2016). Our kids: The American dream in crisis. New York: Simon \& Schuster.

Redondo, M., Hernández-Aguado, I., \& Lumbreras, B. (2018). The impact of the tax on sweetened beverages: a systematic review. The American Journal of Clinical Nutrition, 108(3), 548-563. https://doi.org/10.1093/ajcn/nqy135.

Resnicow, K., \& McMaster, F. (2012). Motivational Interviewing: Moving from why to how with autonomy support. International Journal of Behavioral Nutrition and Physical Activity, 9(1), 19. https://doi.org/10.1186/1479-5868-9-19. 
Resnicow, K., McMaster, F., Bocian, A., Harris, D., Zhou, Y., Snetselaar, L., et al. (2015). Motivational interviewing and dietary counseling for obesity in primary care: an RCT. Pediatrics, 135(4), 649-657. https://doi.org/10.1542/peds.2014-1880.

Robert Wood Johnson Foundation. (2018). The State of Obesity: Better Policies for a Healthier America. Retrieved from https://state ofobesity.org/obesity-rates-trends-overview/

Roseth, C. J., Johnson, D. W., \& Johnson, R. T. (2008). Promoting early adolescents' achievement and peer relationships: The effects of cooperative, competitive, and individualistic goal structures. Psychological Bulletin, 134(2), 223-246. https://doi. org/10.1037/0033-2909.134.2.223.

Ryan, R. M., Deci, E. L., Grolnick, W. S., \& La Guardia, J. G. (2006). The significance of autonomy and autonomy support in psychological development and psychopathology. In D. Cicchetti \& D. J. Cohen (Eds.), Developmental psychopathology theory and method (2nd ed., Vol. 13, pp. 231-253). Hoboken, NJ: Wiley.

Sampson, R. J. (2009). Racial stratification and the durable tangle of neighborhood inequality. The Annals of the American Academy of Political and Social Science, 621(1), 260-280. https://doi. org/10.1177/0002716208324803.

Sandler, I. N., West, S. G., Baca, L. M., \& Pillow, D. R. (1992), Linking empirically based theory and evaluation: The Family Bereavement Program. American Journal of Community Psychology, 20(4), 491-521.

Sargent, J. D. \& Babor, T. F. (2020) The relationship between exposure to alcohol marketing and underage drinking is causal. Journal of Studies on Alcohol and Drugs, Supplement, (s19), 113-124

Sawhill, I. V. (2013). Family Structure: The growing importance of class. Retrieved from https://www.brookings.edu/articles/famil y-structure-the-growing-importance-of-class/

Schaberg, K. (2017). Can Sector Strategies Promote Longer-Term Effects? Three-Year Impacts from the WorkAdvance Demonstration. MDRC. Retrieved from https://www.mdrc.org/sites/default/ files/WorkAdvance_3-Year_Brief.pdf

Shambaugh, J., \& Nunn, R. (2018). Place-based policies for shared economic growth. The Hamilton Project: Brookings.

Sheridan, S. M., Smith, T. E., Moorman Kim, E., Beretvas, S. N., \& Park, S. (2019). A meta-analysis of family-school interventions and children's social-emotional functioning: Moderators and components of efficacy. Review of Educational Research, 89(2), 296-332. https://doi.org/10.3102/0034654318825437.

Spear, B. A., Barlow, S. E., Ervin, C., Ludwig, D. S., Saelens, B. E., Schetzina, K. E., et al. (2007). Recommendations for treatment of child and adolescent overweight and obesity. Pediatrics, 120(Suppl 4), S254-288. https://doi.org/10.1542/peds.20072329F.

Society for Prevention Research. (2018). Graduate Programs in prevention Science. Retrieved from https://www.preventionresearch. org/wp-content/uploads/2019/01/Graduate-Programs-in-Preve ntion-Science-12.2018-2-1.pdf.

St. George, S. M., Wilson, D. K., Schneider, E. M., \& Alia, K. A., (2013). Project SHINE: Effects of Parent-Adolescent Communication on Sedentary Behavior in African American Adolescents. Journal of Pediatric Psychology, 38(9), 997-1009. https://doi. org/10.1093/jpepsy/jst027.

Storr, C., Chen, C., \& Anthony, J. (2004). "Unequal opportunity": Neighbourhood disadvantage and the chance to buy illegal drugs. Journal of Epidemiology \& Community Health, 58(3), 231-237.

Straight Talk on Evidence. (2019). Not all program effects fade: New report on the Project QUEST RCT shows sizable nine-year earnings gains for low-income workers. Retrieved from https://www. straighttalkonevidence.org/2019/04/30/not-all-program-effectsfade-new-report-on-the-project-quest-rct-shows-sizable-nineyear-earnings-gains-for-low-income-workers/
Stringhini, S., Carmeli, C., Jokela, M., Avendaño, M., Muennig, P., Guida, F., et al. (2017). Socioeconomic status and the $25 \times 25$ risk factors as determinants of premature mortality: A multicohort study and meta-analysis of 1.7 million men and women. The Lancet, 389(10075), 1229-1237. https://doi.org/10.1016/S0140 -6736(16)32380-7.

Tax Policy Center. (n.d.). Briefing Book: A citizen's guide to the fascinating (though often complex) elements of the US tax system. Retrieved from https://www.taxpolicycenter.org/briefing-book/ how-do-state-earned-income-tax-credits-work

Townsend, B. L. (2000). The disproportionate discipline of African American Learners: Reducing school suspensions and expulsions. Exceptional Children, 66(3), 381-391. https://doi. org/10.1177/001440290006600308.

U.S. Department of Health and Human Services. (2018). Childhood Obesity Facts. U.S. Department of Health and HumanServices, Centers for Disease Control and Prevention, Oberweight \& Obesity Retrieved from https://www.cdc.gov/healthyschools/obesity/ facts.htm

UNICEF. (2007). Child poverty in perspective: An overview of child well-being in rich countries, Innocenti Report Card 7(7). Retrieved from https://www.unicef-irc.org/publications/445child-poverty-in-perspective-an-overview-of-child-well-being -in-rich-countries.html

Van Dyke, M. E., Komro, K. A., Shah, M. P., Livingston, M. D., \& Kramer, M. R. (2018). State-level minimum wage and heart disease death rates in the United States, 1980-2015: A novel application of marginal structural modeling. Preventive Medicine, 112, 97-103.

Van Ryzin, M. J., \& Roseth, C. J. (2018a). Cooperative learning in middle school: A means to improve peer relations and reduce victimization, bullying, and related outcomes. Journal of Educational Psychology, 110(8), 1192-1201. https://doi.org/10.1037/ edu0000265.

Van Ryzin, M. J., \& Roseth, C. J. (2018). The power of peer influence to address student behavioral problems. Phi Delta Kappan, 99(8), 62-66.

Van Ryzin, M. J., Kumpfer, K. L., Fosco, G. M., \& Greenberg, M. T. (2016). Family-based prevention programs for children: Theory, research, and large-scale dissemination. New York: Psychology Press.

Van Ryzin, M. J., Kumpfer, K. L., Fosco, G. M., \& Greenberg, M. T. (Eds.). (2015). Family-based prevention programs for children and adolescents: Theory, research, and large-scale dissemination. New York: Psychology Press.

Van Ryzin, M., Fishbein, D., \& Biglan, A. (2018). The promise of prevention science for addressing intergenerational poverty. Psychology, Public Policy, and Law, 24(1), 128-143. https://doi. org/10.1037/law0000138.

Wagner, P., \& Walsh, A. (2016). States of incarceration: The global context 2016. Retrieved from https://www.prisonpolicy.org/globa 1/2016.html

Washburn, I. J., Acock, A., Vuchinich, S., Snyder, F., Li, K. K., Ji, P., et al. (2011). Effects of a social-emotional and character development program on the trajectory of behaviors associated with social-emotional and character development: findings from three randomized trials. Prevention Science, 12(3), 314-323. https:// doi.org/10.1007/s11121-011-0230-9.

Weisz, J. R., Kuppens, S., Ng, M. Y., Vaughn-Coaxum, R. A., Ugueto, A. M., Eckshtain, D., et al. (2019). Are psychotherapies for young people growing stronger? Tracking trends over time for youth anxiety, depression, attention-deficit/hyperactivity disorder, and conduct problems. Perspectives on Psychological Science, 14(2), 216-237. https://doi.org/10.1177/174569161880543 6. 
Whitehurst, G. J., \& Croft, M. (2010). The Harlem Children's Zone, Promise Neighborhoods, and the broader, bolder approach to education. Washington, DC: Brown Center on Education Policy at Brookings Institute.

Wilkinson, R., \& Pickett, K. (2009). The spirit level: Why greater equality makes societies stronger. London: Bloomsbury Press.

Wilson, D. K., \& Sweeney, A. M. (2018). The role of behavioral medicine in integrated care. In M. P. Duckworth \& W. T. O’Donohue (Eds.), Behavioral medicine and integrated care: Efficient delivery of the most effective treatments (pp. 9-27). Cham: Springer.

Wilson, D. K., Sweeney, A. M., Kitzman-Ulrich, H., Gause, H., \& St George, S. M. (2017). Promoting social nurturance and positive social environments to reduce obesity in high-risk youth. Clinical Child and Family Psychology Review, 20(1), 64-77. https://doi. org/10.1007/s10567-017-0230-9.

Wilson, D. S. (2019). Excerpt from "This View of Life" by David Sloan Wilson. Retrieved from https://evolution-institute.org/excerptfrom-this-view-of-life-by-david-sloan-wilson/
Wilson, D. S., Hayes, S. C., Biglan, A., \& Embry, D. D. (2014). Evolving the future: toward a science of intentional change. Behavioral and Brain Science, 37(4), 395-416. https://doi.org/10.1017/ s0140525x13001593.

Zarling, A., Bannon, S., \& Berta, M. (2017). Evaluation of acceptance and commitment therapy for domestic violence offenders. Psychology of violence. https://doi.org/10.1037/vio0000097.

Publisher's Note Springer Nature remains neutral with regard to jurisdictional claims in published maps and institutional affiliations. 